\title{
A Qualitative Study of Fathers' Experiences of Depression After Having or Adopting a Child
}

\author{
by
}

\author{
Lilly Pease
}

A thesis submitted to the Faculty of Graduate and Postdoctoral Affairs in partial fulfillment of the requirements for the degree of

Master of Arts

in

Psychology

\section{Carleton University \\ Ottawa, Canada}

(C) 2013

Lilly Pease 


\begin{abstract}
To gain insight into the lived experiences of paternal postpartum and post-adoption depression, semi-structured interviews lasting an average of 73 minutes were conducted with 4 biological and 3 adoptive fathers who self-identified as primary caregivers and experienced depression within 12 months of having or adopting their child(ren). A thematic analysis revealed commonalities and unique aspects of biological and adoptive fathers' experiences of depression, as well as society's influence on their experiences of depression. Commonalities included the impact of Significant Stressors and ExpectationReality Asymmetry on fathers' experiences of depression, while biological fathers had difficulty being Mentally Present with their Children, and adoptive fathers had a Strong Need to Teach their Children. Fathers also described how aspects of society such as Social Expectations of Parents and their Unmet Support Needs perpetuated their depression. These findings are discussed in relation to research regarding mothers' experiences of PPD, and their implications for practice and research are discussed.
\end{abstract}




\section{Acknowledgements}

I would like to thank all of the fathers who participated in this project. Thank you for your openness, your detail, and your appreciation for this research. Your excitement motivated me to see this project through to completion. It was an honour to represent you while writing this document, and my hope is that you are as proud of this project as I am.

I would also like to thank my advisor, Dr. Connie Kristiansen. Your guidance through this project will always be appreciated. You expected a lot from me and, as a result, I expected a lot from myself. Thank you so much for teaching me how to navigate my way through qualitative research. 


\section{Dedication}

For my dad, Wayne Pease. Thank you for your unending encouragement, your hilarious sense of humour, and for showing me how strong a father's love can be. 


\section{Table of Contents}

Abstract ............................................................................ ii

Acknowledgements ............................................................... iii

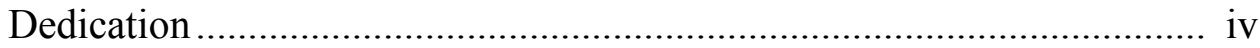

Table of Contents .................................................................... v

List of Tables and Figures......................................................... vii

List of Appendices .............................................................. viii

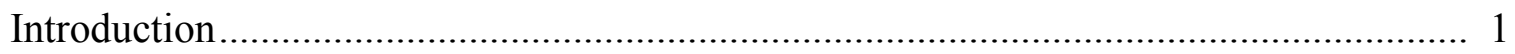

Postpartum Depression ......................................................... 1

Prevalence of Postpartum Depression ........................................... 4

Etiology of Postpartum Depression ..................................................... 5

Paternal Postpartum Depression and Post-Adoption Depression

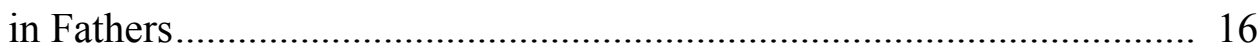

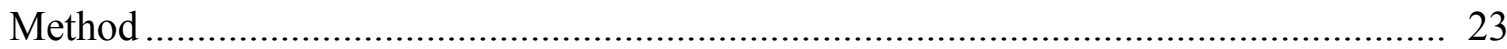

Researcher as Instrument Statement ..................................... 23

Participant Recruitment .................................................. 25

Sources of Data .............................................................. 26

Participants .................................................................. 36

Analysis...................................................................... 42

Efforts to Enhance Research Quality .......................................45 
Results

The Nature of Fathers' Experiences of Depression 48

Commonalities in Biological and Adoptive Fathers' Experiences of

Depression.

Unique Features of Biological and Adoptive Fathers' Experiences of

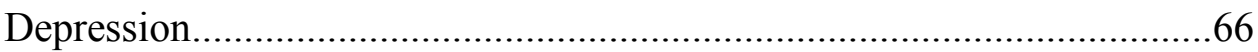

Society’s Influence on Fathers' Experiences of Depression.................. 68

An Additional Interview .............................................................. 73

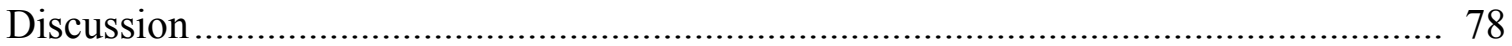

Strengths and Weaknesses of This Study ....................................... 83

Future Research ..................................................................... 86

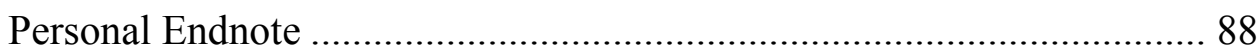

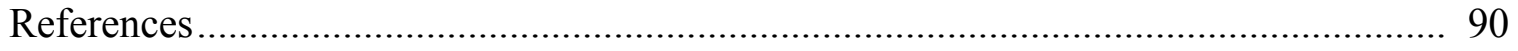

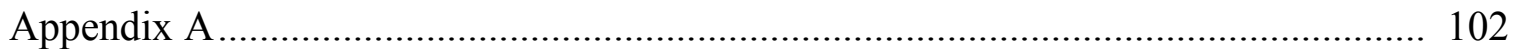




\section{List of Tables and Figures}

Table 1: DSM-IV-TR criteria for Major Depressive Episode .................................... 3

Table 2: Participants' Demographic Characteristics ............................................ 38

Table 3: Participants' Current and Earlier Experiences of Depression ....................... 41

Figure 1: Main themes underlying biological and adoptive fathers' experiences of

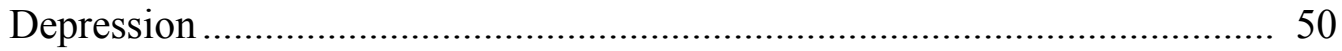




\section{List of Appendices}

Appendix A: Research Materials ........................................................................ 102 


\section{A Qualitative Study of Fathers' Experiences of Depression After Having or Adopting a Child}

Becoming a parent is thought to be the archetypal happy event, filled with an abundance of joy and excitement, this is not always the case (Nicolson, 1998). All too frequently, however, the dreams, hopes and expectations associated with becoming a parent are shattered by the onset of postpartum depression (PPD). Also contrary to prevailing expectations, PPD is not only experienced by biological mothers, it has also been observed among biological fathers and adoptive parents. It is PPD as experienced by biological and adoptive fathers that is the focus of this research because such research is fundamental to understanding the commonalities these two groups share with biological mothers' experiences of PPD. More importantly, however, such research is necessary to appreciate the potentially unique social and situational factors associated with PPD as experienced by fathers.

I begin with a review of the literature, focusing on the clinical features of postpartum depression (diagnostic criteria, prevalence rates, and etiology), biological mothers' experiences with PPD, and the findings of research exploring depression in biological and adoptive fathers.

\section{Postpartum Depression}

Although each woman's experience of postpartum depression is to some extent unique, researchers have documented a number of symptoms often experienced by mothers encountering depression postpartum. Buultjens and Liamputtong (2007) describe such experiences as often characterized by mood fluctuations, feelings of confusion, depression, fatigue or loss of energy, an inability to experience pleasure, sleep issues, difficulty caring for self and/or baby and, in severe cases, suicidal thoughts. 
Feelings of loneliness, hopelessness, anxiety, loss of control, and guilt are also salient in mothers' descriptions of PPD (Leahy-Warren \& McCarthy, 2007). ${ }^{1}$

In the Diagnostic and Statistical Manual of Mental Disorders (DSM-IV-TR; American Psychiatric Association [APA], 2000) a person can be diagnosed with postpartum depression if they meet the specifications for a major depressive episode within four weeks post-delivery. The DSM-IV-TR criteria for a major depressive episode are shown in Table 1. Those diagnosed with a major depressive episode experience symptoms that cause significant distress or impairment in day-to-day functioning. A diagnosis is also warranted when a person consistently experiences a depressive mood or lack of interest or pleasure in activities for at least two weeks, and

\footnotetext{
${ }^{1}$ Many PPD symptoms are similar to those associated with the postpartum blues, a state that 40 to $80 \%$ of women experience during the postpartum period (Chalmers \& Chalmers, 1985; UpToDate, 2011). Like PPD, the postpartum blues also feature rapid mood swings, feelings of anxiety and irritability, and sleeplessness (O'Hara, 1991), experiences that usually develop within two or three days of delivery (Steiner \& Steiner, 1990; UpToDate, 2011). With sufficient social and emotional support, the postpartum blues typically resolve within two weeks (O’Hara, 1991; UpToDate, 2011). In contrast, a diagnosis of PPD requires that the characteristic symptoms be present most of the day, nearly every day for at least two weeks (UpToDate, 2011). Similarly, the symptoms of postpartum psychosis may also be misattributed to PPD. This condition is characterized by delusions, hallucinations, extreme thought disorganization, severe mood swings, and confusion (Lusskin, 2007b; UpToDate, 2011). Postpartum psychosis generally occurs within 1 to 4 weeks postpartum and often requires hospitalization because of the risk of suicide and infanticide (Lusskin, 2007b; Spinelli, 2003; Viguera, Cohen, Baldessarini, \& Nonacs, 2002). Therefore, hospitalization and antipsychotic medication are often required to ensure the safety of both mother and baby (UpToDate, 2011). Although PPD is serious, postpartum psychosis constitutes a "medical emergency" (UpToDate, 2011).
} 
Table 1

DSM-IV-TR criteria for Major Depressive Episode (APA, 2000, p. 356)

A. "Five (or more) of the following symptoms have been present during the same 2-week period and represent a change from previous functioning; at least one of the symptoms is either (1) depressed mood or (2) loss of interest or pleasure.

(1) Depressed mood most of the day, nearly every day (indicated by subject or observed by others).

(2) Markedly diminished interest or pleasure in all, or almost all, activities most of the day, nearly every day (indicated by subject or observed by others).

(3) Significant weight loss when not dieting or significant gain (e.g., a change of more than $5 \%$ of body weight), or decrease or increase in appetite nearly every day.

(4) Insomnia or hypersomnia nearly every day.

(5) Psychomotor agitation or retardation nearly every day (observable by others, not merely subjective feelings of restlessness or being slowed down).

(6) Fatigue or loss of energy nearly every day.

(7) Feelings of worthlessness or excessive or inappropriate guilt (which may be delusional) nearly every day (not merely self-reproach or guilt about being sick).

(8) Diminished ability to think or concentrate, or indecisiveness, nearly every day (either by subjective account or as observed by others).

(9) Recurrent thoughts of death (not just fear of dying), recurrent suicidal ideation without a specific plan, or a suicide attempt or specific plan for committing suicide.

B. The symptoms do not meet criteria for a Mixed Episode.

C. The symptoms cause clinically significant distress or impairment in social, occupational, or other important areas of functioning.

D. The symptoms are not due to the direct physiological effects of a substance (e.g. a drug of abuse) or a general medical condition (e.g., hypothyroidism).

E. The symptoms are not better accounted for by bereavement, (i.e., after the loss of a loved one), the symptoms persist for longer than 2 months or are characterized by marked functional impairment, morbid preoccupation with worthlessness, suicidal ideation, psychotic symptoms, or psychomotor retardation." 
experiences a host of other symptoms, including too much or too little sleep, decreased energy, and ability to concentrate. Also, for a diagnosis of depression these symptoms must not be associated with bereavement, substance abuse, or an underlying medical condition.

Prevalence of postpartum depression. There has been much debate regarding the prevalence of postpartum depression, with rates varying from $4 \%$ to $74 \%$ of postpartum women across studies (Affonso, De, Horowitz, \& Mayberry, 2000; LeahyWarren \& McCarthy, 2007; Matthey, Barnett, Ungerer, \& Waters, 2000). This variability in prevalence rates is largely due to differences in how PPD is assessed (e.g., via selfreport measures vs. clinical interview) and when (e.g., at 6 weeks [Leung, Arthur, \& Martinson, 2005] vs. 12 weeks [Beck \& Gable, 2001] vs. 6 months postpartum [Lusskin, 2007a]), as well as differences in sampling methods, the timescale of the studies, and the sociodemographic characteristics of the sample (Leahy-Warren \& McCarthy, 2007).

Based on their meta-analysis of 59 studies $(N=12,810)$, O'Hara and Swain (1996) suggest that $13 \%$ of postpartum women experience PPD. In a step-wise regression analysis, O'Hara and Swain (1996) found that the best predictor of prevalence rates was time of assessment, with higher prevalence rates observed in studies using longer (e.g., first eight weeks) rather than shorter time frames (e.g., first 4 weeks). This analysis also suggested a small but significant difference between prevalence rates derived from self-report measures (12\%) and diagnostic interviews (14\%). The time of the assessment (i.e., average number of days postpartum) and the location of the study did not predict PPD prevalence estimates. 
Etiology of postpartum depression. When discussing the causation of postpartum depression, researchers have posited both biological and psychosocial accounts. Biological accounts point to the influence of various hormones and genetic predispositions, while psychosocial accounts consider the role of psychological (e.g., feelings of guilt) and social factors (e.g., lack of social support from family or friends) as fundamental to the development of PPD.

Biological accounts of PPD. Guided by a biomedical model, women's experiences of PPD have been attributed to various hormonal imbalances (Buultjens \& Liamputtong, 2007; Littlewood \& McHugh, 1997), particularly the rapid drop in reproductive hormones that occurs following childbirth (Wisner, Parry, \& Piontek, 2002). Consistent with this, the findings of Bloch et al. (2000) directly support the involvement of estrogen and progesterone in the development of PPD. To explore the role of declining hormonal levels in the development of postpartum depression, these researchers simulated the following hormonal conditions in 16 women who were neither pregnant nor depressed. Exactly half of these women had a history of PPD. These researchers administered leuprolide to each of these women in order to create a hypogonadal state, and then gave them supraphysiologic doses of estradiol and progesterone for eight weeks (Bloch et al., 2000; Wisner et al., 2002). Following the removal of the estradiol and progesterone, which was done under double-blind conditions, five women with a history of PPD experienced depressive symptoms, whereas none of the participants without a history of PPD reported such symptoms. Given these findings, Bloch et al. (2000) concluded that declining hormone levels play a significant role in the development of 
PPD; specifically, that women with prior experiences of PPD are particularly sensitive to the mood-destabilizing effects of gonadal steroids.

Other researchers posit that progesterone levels are associated with the development of postpartum blues, but not the development of PPD (measured at five to six weeks postpartum; Harris, 1996). Harris (1996) speculates that postpartum blues can be accounted for by considering how progesterone levels rise during pregnancy and rapidly drop after giving birth, creating temporary "withdrawal from an endogenous benzodiazepine like agent" (p. 32). Other biochemicals, such as thyroid hormones, cholesterol, and cortisol, have also been implicated in the development of PPD (Lusskin, 2007a; McCoy, 2003). Overall, then, while a number of studies confirm the influence of hormones on the development of PPD, researchers have yet to agree on the extent to which hormones directly affect the development of PPD (Treloar, 1999).

Genetic predispositions have also been given a role in the development of PPD. Treloar and colleagues (1999) analysed retrospective interview and questionnaire data from 838 female twin pairs, all of whom had experienced one or more live births. The results of their analyses suggest that genetic factors account for $38 \%$ of the variance (heritability) in PPD symptoms, an estimate comparable to that for depression outside the postpartum period $^{2}$ (Treloar, 1999). Steiner, Dunn, and Born (2003) suggest that genetic factors may contribute to PPD and other mood disorders via their impact on how people interpret and react to stressful life events, which manifests in changes in the neuroendocrine system. In particular, Steiner et al. postulate that women experience

\footnotetext{
${ }^{2}$ Rates of depression occurring outside of childbirth vary from 21 to $45 \%$, depending on the definition of depression (Kendler, Neale, Kessler, Heath, \& Eaves, 1992).
} 
more mood disorders than men due to their elevated genetic predisposition, greater exposure to stressful events, fluctuating gonadal hormones, or an amalgamation of any of these factors.

Both pharmacological treatments and psychotherapy are the standard treatments for postpartum depression (Appleby, Warner, Whitton, \& Faragher, 1997; Green \& McCabe, 2012; O’Hara, Stuart, Gorman, \& Wenzel, 2000; Stuart, 2012). However, consistent with such biomedical accounts of PPD, women with severe symptoms of PPD (e.g., a history of suicidal behaviour or psychosis) are most effectively treated pharmacologically (Green \& McCabe, 2012; Yonkers et al., 2009).

Psychosocial accounts of PPD. While biological factors may play a role in PPD, other researchers regard psychosocial factors as more central to the development of PPD. Consistent with this, the strongest predictors of PPD are history of psychopathology and psychological disturbance during pregnancy (e.g., dysphoric mood), poor marital relationship, low levels of social support (e.g., from the baby's father), and stressful life events (e.g., loss; O’Hara \& Swain, 1996). O’Hara and Swain's (1996) depiction of the prototypical woman at risk for PPD draws attention to the contribution of these factors to PPD:

She is most likely to occupy a lower social stratum but women representing middle and upper social strata will also be abundantly represented. She is very likely to have experienced life stressors during pregnancy and may have had a more difficult than normal pregnancy or delivery. She will be experiencing marital difficulties and experience her partner as providing little in the way of social support. Compounding the life stress she is experiencing and her poor 
marital relationship will be her perception that others in her social network are not particularly supportive of her. Finally, her history will show evidence of psychopathology, in most cases major depression or dysthymia, and she will show evidence of being at least mildly depressed and anxious, and excessively worried. (p. 46).

A number of qualitative studies have yielded findings consistent with a psychosocial account of PPD. Based on her longitudinal in-depth interviews with 24 women, Nicolson (1998) contends that rather than pathologizing PPD, society needs to reconceptualise PPD as "part of the normal experience of most women when they become mothers (pp. 108-109)." The postpartum period is a time of tremendous change. These changes include physiological changes in the body, changes in bodily functions (e.g., the biological function of the breasts becomes salient) and body shape, and a host of social changes. Consistent with this, all of the women in Nicolson's (1998) study lamented changes in their physical appearance (pre- vs. post-baby) and changes in the amount of quality time they had with their partners, among other things.

More important to the women's experiences of PPD, however, was the loss of their sense of their autonomous identity. One woman expressed her uneasiness about not having her own income and those not returning to work after having a baby described missing the companionship and interactions with co-workers. As Nicolson (1998) put it, "occupational identity was for all in various ways an important part of their sense of who they were. This loss was a loss of how they had experienced their lives before the baby, as successful and independent" (p. 93). Unfortunately, many of these women were unable to consciously acknowledge these feelings of loss, even to themselves. Because 
some people perceive an "ideological symmetry" between woman and mother ${ }^{3}$ (also mentioned in Weaver \& Ussher, 1997, p. 88), Nicolson suggests that it is socially unacceptable for women to grieve the loss of their pre-motherhood, autonomous selves. As a result, "women are actively prevented from mourning their losses because of social constraints and the unconscious acceptance of those constraints" (Nicolson, 1998, p. 93). Fortunately, however, by the last interview the women acknowledged that, although it took time to overcome the challenges associated with the changes in becoming a mother, their feelings of loss had dissipated.

The contribution of psychosocial factors to PPD is also highlighted by research documenting that, not only is social support an important causal factor in the development of postpartum depression (O'Hara \& Swain, 1996; Wilson et al., 1996), it is also central to women's recovery from PPD. In a Canadian study (Letourneau et al., 2007), mothers with PPD described having a variety of support needs, with the particular support desired by each woman reflecting her unique experience of PPD. For example, mothers regarded informational support (e.g., teaching regarding PPD) and instrumental support (e.g., help tending to the baby) as most valuable when their symptoms of PPD were the most unmanageable. Affirmational support (e.g., validation), in contrast, was most desirable after women's informational and instrumental support needs were met. In this regard one participant stated, "Once you've got your [child care and household] routines down and you are on top of that game. Then you need the mental working-out, then you need the counseling" (Letourneau et al., 2007, p. 445). The affirmational

\footnotetext{
${ }^{3}$ For some, being a mother is so integral to a woman's identity that to be a woman is to be a mother.
} 
support of another mother who had experienced PPD (e.g., peer support) was deemed most valuable.

Letourneau et al. (2007) also found that the unavailability of the desired type of social support detracted from mothers' ability to cope with the extra stress and ongoing symptoms of PPD. For example, mothers reported feeling isolated and overwhelmed with anxiety because they were their infants' primary caregivers. Some mothers also reported feeling alone both during their adjustment to parenthood and while dealing with the onset of their depressive symptoms.

Consistent with a psychosocial account of PPD, support in the form of psychotherapy (e.g., cognitive behavioural therapy) has been shown to be particularly effective for women with mild to moderate symptoms of PPD (Chabrol et al., 2002; Green \& McCabe, 2012). However, formal sources of support (e.g., counselling) are not necessarily required for the effective treatment of PPD. Indeed, some of the mothers in Letourneau et al.'s (2007) study preferred one-on-one support from someone who understood or had experienced PPD, be it a neighbour, family member, or professional.

To gain a more integrated understanding of the psychosocial nature of women's experiences of PPD, Beck (2002) conducted a "meta-synthesis" of the findings from 18 qualitative studies of women with PPD. ${ }^{4}$ Meta-synthesis is a method that considers "the theories, grand narratives, generalizations, or interpretive translations produced from the integration or comparison of findings from qualitative studies" (Sandelowski, Docherty, \& Emden, 1997, p. 366). These studies, conducted in Canada, the USA, the United Kingdom, and Australia, were published between 1990 and 1999 and included data from

\footnotetext{
${ }^{4}$ Nicolson's (1998) study was included in this meta-synthesis.
} 
309 mothers. This meta-synthesis revealed four major themes underlying women's experiences of PPD, namely “(a) incongruity between expectations and reality of motherhood, (b) spiraling downward, (c) pervasive loss, and (d) making gains" (Beck, 2002, p. 3).

Regarding the first theme, "incongruity between expectations and reality of motherhood," women in 8 of the 18 studies described their expectations of motherhood as unrealistic (Beck, 2002). For example, the women in Berggren-Clive's (1998) study described not having their expectations met in regard to labour and delivery, the support they received from family members and friends post-delivery, their post-delivery relationships with significant others, and the physical changes in their bodies after pregnancy and giving birth. One participant vividly described how the reality of her birthing experience was extremely different than the one she had hoped for, stating: I believe that I lost my chance of being happy, having a baby and having all those things you see. A husband beside you, the baby is coming out, the doctor is smiling, everybody is smiling. I didn't know this. As a matter of fact, both babies of mine had to be taken away from me. With the first baby I was 36 hours in labour and I was so exhausted. With the second baby they brought him to me and I kissed him a bit and I started hemorrhaging. So other women take the baby and have the baby in your room. I didn't have that. It was like I was being punished. (Berggren-Clive, 1998, p. 110). Another woman lamented over her partner not fulfilling her support needs, saying "I just thought he would know what I needed. I just had a baby here. I don't care if you are tired, I don't care if you have a new job. The focus should be on me and it's not" (Berggren-Clive, 1998, p. 110). Yet another participant described her unfulfilled expectations for social support when she said, "I was alone here. I didn't have the people I always dreamed of having, like my mother. My mother was not here with both babies. 
My friends, my good friends, I was alone” (Berggren-Clive, 1998, p. 111). Finally, one woman described physical changes that included overwhelming exhaustion. As she put it, "I came home with high expectations and hopes, I was feeling that I would make it and everything would be fine but physically I was so exhausted I thought I would collapse” (Berggren-Clive, 1998, p. 111).

Beck's (2002) meta-synthesis revealed that "spiraling downwards," the second of the four themes she identified, was pervasive in women's experiences of PPD and apparent in each of the 18 studies she reviewed. This spiralling downward was evident in women's emotions and cognitions and included anxiety, anger, guilt (e.g., over not experiencing a strong emotional bond with her infant), obsessive thoughts (e.g., regarding failing as a mother), loneliness, feeling overwhelmed, and contemplating harming oneself.

The third theme, pervasive loss, appeared in the accounts of the women from 15 of the 18 studies (Beck, 2002). The types of loss varied across studies and included loss of control (Beck, 1993), loss of autonomy, identity, and former physical appearance (Nicolson, 1999), loss of relationships (e.g., difficulty coping with their infant caused mothers to push their older children away; Beck, 1996), loss of friendships (e.g., women felt different than other mothers so they withdrew from these friendships; Mauthner, 1995), and loss of voice (e.g., women silenced their voices out fear of being misunderstood, criticised or rejected if they spoke honestly about their feelings and experiences; Mauthner, 1998).

However, results from Nicolson's (1999) study indicate that most mothers experiencing PPD were able to accept the changes associated with loss. For example, 
these mothers accepted that the loss of their formerly autonomous self was a natural consequence of motherhood. Beck (2002) notes that women experiencing PPD felt more in control of their lives when they acknowledged their needs and found ways of meeting those needs. Further, the women in Mauthner's (1998) study reported that “acceptance or resolution" of the changes and conflicts associated with the loss that they experienced was crucial to their recovery (Beck, 2002).

The last theme, apparent in 11 of the 18 studies, involved the features of women's recovery process. Some women described how their experiences of PPD were underrated or discounted when they sought professional help (Berggren-Clive, 1998). Others mentioned feeling frustrated, humiliated, and angry when they sought help for their depression (Beck, 1993). However, in a number of studies the women described PPD support groups as extremely beneficial because they helped them feel like they were not alone in their experiences of PPD (Berggren-Clive, 1998) and because they facilitated dialogue regarding their unrealistic and/or unfulfilled expectations of motherhood (Mauthner, 1995). Consequently, adjusting their expectations of themselves and others (Berggren-Clive, 1998) played an important role in women's recovery from PPD.

In sum, each of these qualitative studies offers findings consistent with a psychosocial account of PPD. This does not mean, however, that there is no room for biological factors to play a role. Indeed, given the mind-body relation (Meissner, 2006), it is likely that both psychosocial and biomedical factors interactively contribute to the development of PPD (Dennis, Janssen, \& Singer, 2004; Miller, 2002).

Other evidence for the psychosocial account of PPD comes from research with adoptive mothers, as the possible biological contributions to PPD are irrelevant with this 
group of mothers. Although not studied extensively (Payne et al., 2010), women's experiences of post-adoptive depression have been documented (Gair, 1999; Handford, 1985; Payne et al., 2010; Senecky et al., 2009). In a study by Payne et al. (2010), 86 adoptive mothers of infants under one year of age completed a modified version of the Edinburgh Postnatal Depression Scale (EPDS; Cox, Holden, \& Sagovsky, 1987) at three times. At 0 to 4 weeks post-adoption significant depressive symptoms were found in $30 \%$ of these adoptive mothers, at 5 to 12 weeks depressive symptoms were found in $26 \%$, and by 12 to 52 weeks post-adoption only $13 \%$ of the adoptive mothers showed significant depressive symptoms. Further, while depressive symptoms were not associated with personal or family psychiatric history, they were associated with postadoption stress and adjustment difficulties with the child. For example, $22 \%$ of all of the adopted children had special needs, including developmental delays, birth defects, and HIV infection. Payne et al. therefore concluded that post-adoptive depression is common within the first year of adoption and primarily associated with environmental stressors rather than genetic factors.

As is true of biological mothers with PPD, adoptive parents' unfulfilled expectations contribute to their adjustment difficulties. Foli (2010) conducted in-depth semi-structured interviews with 21 adoptive and kinship participants ${ }^{5}$ (20 mothers and 1 father) who self-identified as having experienced depression during a post-adoptive period within the last two years. The salient theme in these parents' post-adoption

\footnotetext{
5 "The majority of kinship parents were grandparents; one participant was an aunt who had adopted her niece... Kinship parents were included in the study as kinship was seen as another context or path to adoption" (Foli, 2010, p. 383).
} 
accounts involved unfulfilled or unrealistic expectations of the self, the child, family/friends, and society. Unrealistic self-expectations were common among these participants, especially given the self-presentation pressures associated with the scrutiny of the adoption process. This 'ideal parent' self-depiction was subsequently rattled when, like all parents, these adoptive parents encountered the challenges of parenting.

In addition, these parents sometimes had unrealistic expectations of the adopted child, even if they had been informed that their child had particular needs or difficulties. Some adoptive parents underestimated the effects of living in a foster home or orphanage on a child, effects that may include shrieking in order to get attention. One participant compared adopting a child to an arranged marriage, stating that that the "assumption of a 'perfect match' was only an assumption” (Foli, 2010, p. 393). Such unrealistic expectations of the child made the initial integration of the child into the adoptive family a difficult and sensitive task (Foli, 2010). They also paved the way for depression.

As is true of biological mothers, the unfulfilled expectations of family, friends, and others also contributed to adoptive parents' feelings of depression. For example, one adoptive mother lamented over the fact that her parents treated her adopted children differently than the 'real grandchildren'. These depressed adoptive parents also commented on the frequency with which family, friends, and/or strangers asked inappropriate questions about the adoption; questions that some of the adoptive parent(s) were uncomfortable answering (e.g., regarding infertility or adoption costs). Ultimately, this lack of support left these adoptive parents feeling marginalized (Foli, 2010).

In addition to interviewing adoptive parents, Folio also interviewed 11 experts in the adoption sector, including psychologists specializing in domestic adoptions, social 
workers experienced in domestic and international adoptions, professionals proficient on attachment, and a specialist in postpartum depression. These experts provided rich data regarding the emotional ramifications of the adoption process on adoptive parents. One professional explained how many adoptive parents have a difficult time coming to terms with post-adoption depression, and even their decision to become an adoptive parent. This adoption expert suggested that society's lack of understanding of post-adoption depression as a mental health issue can result in people questioning the adoptive parent's reasoning and fervent desire to adopt, saying things such as "you have faulty judgment," “you rushed into this," or "you didn’t think it through" (Foli, 2010; p. 395).

It is interesting to note that from the medical model perspective, when a biological mother experiences PPD, a biological account attributes PPD to the mother's body (i.e., her fluctuating hormones) whereas when an adoptive mother experiences post-adoption depression, many in society attribute the 'problem' to her ill-considered decisions (e.g., she rushed into adoption and did not think it through). Regardless of how a woman becomes a mother, she is held responsible for any depression she experiences.

\section{Paternal Postpartum Depression and Post-Adoption Depression in Fathers}

Discussions of PPD in both the research literature and the popular media typically focus exclusively on the experiences of biological mothers. However, biological and adoptive fathers also experience the stress and life changes associated with the arrival of a new baby. With this in mind, it is not surprising that both biological and adoptive fathers also experience PPD.

Postpartum depression in biological fathers. To date, most researchers concerned with fathers has focused on fathers' responses to partners who have maternal 
PPD (e.g., Davey, Dziurawiec, \& O’Brien-Malone, 2006; Meighan, Davis, Thomas, \& Droppelman, 1999) rather than fathers who themselves have PPD. For example, Meighan, et al. (1999) interviewed eight men regarding their experiences with spouses/partners living with PPD. These men stated that their female partner's depression was a major source of disruption in both their lives and their relationships with their partners. These men also expressed feelings of concern for their partners, fear, confusion, and distress over not being able to find a solution for the "problem" (Meighan et al., 1999).

Other research has examined fathers' experiences of postpartum depression, albeit relative to the experiences of their female partners. Along these lines, Ballard and Davies (1994) had mothers and fathers complete the Edinburgh Postnatal Depression Scale (EPDS; Cox, Holden, \& Sagovsky, 1987) at six months postpartum. They then conducted individual semi-structured interviews with the members of 200 couples where both members were experiencing PPD, as indicated by an EPDS score of 13 or more. During the interviews symptoms not measured by the EPDS (e.g., nervous tension, loss of libido, hypochondriasis) were assessed using the Psychiatric Assessment Schedule (Dean et al., 1983). Analyses of these data indicated that, although mothers $(M=11.0)$ experienced more symptoms than fathers $(M=9.8)$, the type of symptoms fathers experienced were notably correlated with those experienced by their female partners, $r=$ .50. To account for these findings, Ballard and Davies (1994) suggested that fathers' experiences of PPD were either less severe than mothers' experiences or that the fathers underreported their symptoms. 
Subsequent research has confirmed Ballard and Davies' (1994) findings. Matthey et al. (2001) had 208 fathers and 230 mothers complete the EPDS at six weeks postpartum and, while there were no gender differences in responses to three items assessing self-blame, unhappiness causing sleep difficulties, and self-harm ideation, for the remaining 7 EPDS items women reported more difficulties than men. Overall, Matthey et al. (2001) stated that men's less frequent endorsement of the items in the EPDS is not surprising given that the rates of depression more generally are lower in men than women. However, they also noted that men may be less likely than women to endorse some EPDS items (e.g., the item assessing crying) because men generally express their unhappiness in other ways. With these points in mind, Matthey and colleagues (2001) recommended a slightly lower cut-off score when screening for the symptoms of PPD in fathers.

Paternal postpartum depression (PPPD) has now been identified as a valid construct in its own right. In their meta-analysis of 43 studies, Paulson and Bazemore (2010) found an overall rate of PPPD of $10 \%$ between the first trimester of pregnancy and the first postpartum year. The lowest rate of paternal depression, $7.7 \%$, was observed in the first 3 months postpartum and the highest rate, almost $27 \%$, occurred between 3 and 6 months postpartum. No explanation for the shift in prevalence rates over time was provided. Twenty-two of the studies included in this meta-analysis also reported partners' maternal depression rates between the first trimester of pregnancy and the first postpartum year. Analyzing these data revealed a rate of maternal depression of $24 \%$, with higher rates (42\%) occurring 3 to 6 months postpartum. In addition, there was a moderate positive relation between paternal and maternal depression within couples, $r=$ 
.31 (for comparable findings see Ballard, Davis, Cullen, Mohan, \& Dean, 1994;

Bielawksa-Barorowicz, \& Kossakowska-Petrycka, 2006; Goodman, 2008; Matthey, Barnett, Kavanagh, \& Howie, 2001; Matthey et al., 2000; Paulson, \& Bazemore, 2010).

Like mothers experiencing PPD, higher PPPD rates are observed among fathers with less social support from family members and friends (Bielawksa-Barorowicz \& Kossakowska-Petrycka, 2006; Deater-Deckard, Pickering, Dunn, \& Golding, 1998; Durkin, Morse, \& Buist, 2001). Fathers with a history of depression also appear to be more susceptible to the development of PPPD (Areias, Kumar, Barros, \& Figueiredo, 1996).

Despite findings indicating that men experience paternal PPD, there is little understanding of fathers' lived experiences of PPD. In one of the few studies examining fathers' experiences of PPD, Gao, Chan, and Mao (2009) examined fathers' experiences of postpartum stress and social support within the context of their study of co-occurring maternal and paternal postpartum depression. Specifically, these researchers conducted a cross-sectional study exploring depression, perceived stress, and social support in 130 new-parent couples. Both the mother and father of each couple individually completed the EPDS (Cox et al., 1987), the Perceived Stress Scale (Cohen, Kamarck, \& Mermelstein, 1983), and the Social Support Rating Scale (Xiao \& Yang, 1987). Analyses of these data indicated that $13.8 \%$ of the mothers and $10.8 \%$ of the fathers scored greater than 13 on the EPDS, indicating experiences of PPD. Additionally, while mothers and fathers did not differ in their perceptions of being stressed, fathers reported having significantly less postpartum social support than mothers. Further, for both mothers and fathers, higher perceived stress scores were associated with moderately 
higher EPDS scores ( $r \mathrm{~s}=.52$ and .58 , respectively) and more social support was associated with lower EPDS scores ( $r \mathrm{~s}=-.57$ and -.68 , respectively). Finally, for both groups, more social support was associated with slightly lower levels of perceived stress $\left(r \mathrm{~s}=-.20\right.$ and -.13 for mothers and fathers, respectively). ${ }^{6}$ Given that social support was related to the severity of both mothers' and fathers' PPD, fathers' relative lack of support is an issue that merits further attention.

While the findings of quantitative studies such as that of Gao et al. (2009) add to the body of knowledge regarding fathers' experiences of PPD, such studies do not provide a broad, contextualized understanding of fathers' experiences of PPD. For example, how is that fathers experience less social support than mothers? Is it because people fail to provide fathers with support as a result of gender stereotypes that suggest that fathers are unlikely to be adversely affected by parenthood? Do fathers actively seek assistance? Are there perceived barriers that prevent fathers from seeking assistance? Clearly these and countless other areas related to fathers' experiences of PPD merit investigation.

Post-adoption depression in fathers. Like biological parents, adoptive parents experience an emotional rollercoaster while preparing for a new child. Indeed, during this time adoptive parents may shoulder even more stress than biological parents given the uncertainty, financial burden, potential for disappointment and personal scrutiny associated with the adoption process (Payne, Fields, Meuchel, Jaffe, \& Jha, 2010). Given the stress occurring throughout the process of adopting a child, it is unsurprising that adoptive fathers experience post-adoption depression. This was documented in a study

${ }^{6}$ All correlations mentioned were statistically significant at $\mathrm{p}<.01$ 
conducted by Foli (2010) who, in addition to conducting interviews with adoptive parents, also observed two adoptive parent support groups (one for mothers and one for fathers, with 12 to 15 participants per group). Foli found that fathers in the support group reported feeling angry (e.g., because they had not been given the necessary support or information from adoption placement professionals), extremely overwhelmed, and experienced depression.

Unfortunately, research exploring fathers' experiences of post-adoption depression is severely limited; regardless of the methodology used (e.g., quantitative or qualitative research methods). Indeed, based on their literature review McKay, Ross, and Goldberg (2010) described the exclusion of adoptive fathers as a major limitation in postadoption mental health research. Consistent with this, only one of the 21 adoptive parents in Folio's (2010) study of depression was an adoptive father. Therefore, because previous research has primarily focused on the experiences of post-adoption depression in mothers (using both quantitative [e.g., Payne et al., 2010] and qualitative [e.g., Foli, 2010] research methods), there is a significant need for future research exploring adoptive fathers' experiences of post-adoption depression.

When having a child, biological and adoptive parents experience many of the same stressors, including the disruption of routines, sleep deprivation, and a host of lifestyle changes. In addition, however, each group experiences a number of unique stressors. For example, only biological mothers experience the hormonal changes associated with pregnancy and giving birth, and only adoptive parents have the potential to experience the negative feelings associated with infertility (Payne, 2010). Similarly, only fathers are likely to experience the impact of masculine gender expectations. In 
particular, because PPD is typically associated with biological mothers, fathers may have very different experiences considering and/or seeking support for their depression.

A qualitative study was conducted in order to gain further insight into how biological and adoptive fathers experience depression in the postpartum and postadoption period. Although previous research has established that men experience paternal postpartum depression, to date this research has failed to shed light on the breadth and depth of these men's lived experiences. Also, although some researchers (e.g., Foli, 2010; Payne et al., 2010) have conducted informative studies of mothers' experiences of post-adoptive depression, this research left substantial room for the exploration of fathers' experiences of post-adoptive depression. Therefore, the purpose of the current study was to explore the phenomenon at a deeper level by examining how both biological and adoptive fathers experience depression after having or adopting a child in their own terms and in greater detail. 


\section{Method}

\section{Researcher-as-Instrument Statement}

My research-related thoughts, goals, and practices are firmly rooted in a constructivist/interpretivist paradigm (Ponterotto, 2005) that "emphasizes the goal of

understanding the lived experiences (Erlebnis) from the point of view of those who live it day to day" (Schwandt, 1997, pp. 135-136). This philosophy is well-suited to the focus of this study, which concerns the experiential realities of fathers experiencing postpartum depression. My knowledge of qualitative research is considerable, as I have studied this research method in two courses at the undergraduate and graduate level. Furthermore, I have applied this knowledge and developed my skills as a researcher in four qualitative projects, all using the thematic analysis method.

My motivation for pursuing this research is attributable to my own life experiences of being raised by a primary caregiver living with depression that began in the form of postpartum depression. Although she was a primary caregiver, I know my mother's experience of depression is likely to differ from those of others with PPD, particularly primary care-giving biological and adoptive fathers. Because a researcher's own life experiences often inspire or motivate the areas or topics they choose to study (Banister, 1999; Ellingson, 1998; Finlay, 2002), like other qualitative researchers I "acknowledge that the very nature of the data we gather and the analytic process in which we engage are grounded in subjectivity" (Morrow, 2005, p. 5).

In line with the constructivist/interpretivist philosophy underlying this research, I also acknowledge the role of my subjectivity as it manifests as participants and I coconstruct meaning during data collection and as I engage in analyzing and interpreting 
these data (Morrow, 2005). Because of this, I have engaged in reflexivity throughout the research process, by which I mean a "process of critical self-reflection on one's biases, theoretical predispositions, preferences, and so forth" (Schwandt, 1997, pp. 135-136). Added to this, I have embraced my subjectivity during the research process as it has provided me with a baseline against which to compare and understand the experiences of others (Banister, 1999). I have done this by journaling about my research-related thoughts, reactions, insights and new understandings from the beginning of this project until its completion (Morrow, 2005).

Keeping this reflexive journal was fundamental to the completion of this research project as it provided a space where I could document my thoughts and feelings and see them develop throughout the research process. For example, after the first interview I was left doubting whether or not I could continue researching this topic. At that point I realized that I was unprepared for, and extremely naïve about, the complexities involved in researching fathers' experiences of depression. In particular, while I was equipped to talk about depression, I was entirely surprised by the first participant's discussion of physical, emotional, and sexual abuse. Regretfully, because I did not consider the possibility of this topic surfacing during the interviews I was caught off guard when multiple instances of horrendous abuse were disclosed by participants. As a result, completing these interviews left me feeling emotionally raw, sometimes angry, and always full of questions. In my reflexive journal I documented questions such as "Why do we live in a world where children are sexually violated?" "How can a mother not do anything when she knows her husband is molesting their daughters?" "How come those who desperately want to conceive a child can't, yet someone who does not want a child 
can?" "Why does this amazingly intelligent man want to end his life?" These questions dominated my thoughts daily. Returning to my office after the first interview, all I could do was sit and cry. After the second interview, my response was the same. These interviews left me motionless, drained, and questioning if I was strong enough to continue this project. Writing in a reflexive journal provided me with the space I needed to work through these and other questions, emotions, and struggles. It provided a space to critically reflect on these thoughts, feelings, and potential biases that were developing; maintaining awareness and insuring they did not negatively influence my behaviour during subsequent interviews and my interpretations during the data analysis. ${ }^{7}$

\section{Participant Recruitment}

Posters calling for fathers who self-identified as primary caregivers who had experienced depression within 12 months of having or adopting a child to take part in a study were posted in daycare agencies, community health centres, men's change rooms at two gym chains, parent/child play groups, doctors' offices, libraries, and family services offices in Ottawa, Toronto, Kitchener, Waterloo, London, and Sarnia, Ontario (see Appendix A for all of the research materials). Presentations were also given to adoption

\footnotetext{
${ }^{7}$ In addition to writing in my reflexive journal, I reached out to my partner to talk about what was going through my mind after the first couple of interviews. Although he was completely supportive of the research project, he already felt emotionally drained from his work as a registered nurse. He dealt with death on a regular basis, and I found that debriefing with him emotionally depleted him even more. At this point I turned to my graduate supervisor who had significant qualitative research experience with the topic of depression. I vocalized how I was struggling to keep participants' experiences from dominating my thoughts, and how this was negatively impacting my ability to fall asleep. In addition to listening intently, she also offered helpful tips on how to keep my thoughts and emotions balanced. These conversations were cathartic and encouraging, and I used her advice throughout the duration of the research process.
} 
support groups, social workers, counsellors, and management at various community service/support offices. Added to this, psychologists and family counsellors specializing in depression were given information about the study to pass on to anyone who might be interested in participating and organizations such as the Father Involvement Research Alliance and The Adoption Source posted the call for participants on their official websites. To increase the diversity of participants' characteristics (e.g., social economic status, education level, marital status), I contacted a variety of organizations tailored to unique client needs. For example, some organizations offered free services such as counselling and workshops, whereas others required paid memberships. Because there are generally fewer adoptive than biological fathers, and I wanted balanced representation of both types of fathers, I devoted special attention to reaching out to adoption resources (e.g., the Children's Aid Society).

When contacted via email or phone I informed potential participants that the study was being conducted to gain insight into primary caregiving fathers' experiences with depression within a year of having or adopting a child. I also told them that their participation would involve taking part in a 60 to 90 minute audio-recorded interview regarding their experiences and completing a demographic information sheet and a measure of postpartum depression (EPDS; Cox et al., 1987). A mutually convenient time and location (e.g., Carleton University campus, public library, community centre) for the interview was then arranged with those who wished to participate.

\section{Sources of Data}

The primary source of data came from semi-structured interviews. Other data came from paper-and-pencil measures, namely a questionnaire regarding their 
demographic characteristics and the EPDS, as well as a post interview comment sheet that I completed.

The interviews. In the face-to-face semi-structured interviews, which varied in length from 57 to 97 minutes ( $M=73$ mins.), I started by asking participants an easy-toanswer open-ended question, namely why they decided to take part in this study. Starting this way helped to establish some rapport with participants and gave them a sense of their ability to participate (Rubin \& Rubin, 1995). The interview then progressed from lighter questions (e.g., "How many children do you have?" "What made you decide to participate in this study?") to more sensitive and emotionally demanding questions regarding their experiences of depression. This structure was especially important for participants with a history of abuse (e.g., sexual and partner abuse), as these participants recounted their history while discussing experiences of depression. For example, when explaining how he copes in overwhelming situations, George said that he responds with anger, which is analogous to how he coped after being sexually abused by a priest as a child. It is apparent that the coping mechanisms George uses while experiencing depression are intertwined with the mechanisms he used as a child. Therefore the structure of the interview guide was appropriate as it focused on coping mechanisms toward the end of the interview.

I asked the remaining questions, shown in the interview guides in Appendix A, in a way that respected the natural flow of conversation. These questions pertained to fathers' transition to becoming a primary caregiving father, their expectations regarding this transition, their experience of depression, how they coped with this, any support they received, and other aspects of their experience they wanted to share. 
These questions were designed to touch on a range of factors that may have contributed to or exacerbated participants' symptoms of depression. Certain topics, such as lack of social support and unfulfilled or unmet expectations, have been identified as important to women's experiences of postpartum depression. However, because those participating in this study were fathers, it was imperative that I remain sensitive to possible differences between women and men's experiences of postpartum depression. Other topics, such as possible barriers preventing primary care-giving fathers from seeking social support, were of particular interest given that these primary caregivers were male.

As I am not a man, father, nor primary caregiver, I was apprehensive about asking certain questions; worried that the questions may be inappropriate, inapplicable, or naïve. Therefore, during the design of the interview guide I contacted a family friend who is father and the primary caregiver of his two young children. He graciously answered questions about his experiences as a father and primary caregiver, and these responses helped inform some of the questions that I asked participants. For example, when asked if there were any barriers that prevented him from seeking social support or asking questions, he responded:

When I decided to stay home with [my daughter], [my wife] would say, "Oh, there are lots of men who stay home with their children." And I'd be at the park or the playground with [my daughter], surrounded by moms and nannys, the only man in sight. And I would say, "Where are all these men?" I found being home with [my daughter] to be very lonely at times. I knew no other men who were at home with their kids while I was home. There is a perception that a father who stays home must have had trouble finding work. There are still a lot of "Mr. Mom" jokes. Not many moms will invite a dad and child over for a play 
date. The entire parenting industry is geared toward moms. Just flip through the pages of Today's Parent magazine and you will see lots of ads for cosmetics, but not too many for chicken wings, football, or NASCAR. There are very few change tables in mens' washrooms. The parking spots close to the door are for "moms and babies." The low-volume movies that they play in the afternoons are "Movies for Mommies." There are few, if any, mens' parenting support groups, to my knowledge. When my daughter went to public school, and the school called home with a problem, they called my wife and the nanny. They never called me, even though they had my number.

As a result of this father's response, I included the following questions in the interview guide: "Did you ever ask anyone for help? If not, why? What stopped you? Did/does anyone give you any kind of support (family/ friends/ community/ professionals)? What kind of support? Were there any things that you felt you needed but didn't get?"

To ensure that the interviews were informative and had depth, detail, and breadth (Rubin \& Rubin, 1995, 2011), I used probes and asked for examples for responses that needed clarification or additional detail. I also used follow-up questions for any unanticipated topics raised by the participants and, following Kvale's (1996) suggestion, I asked questions to verify my understandings of participants' responses.

The research involved an ongoing iterative process of developing the interview, collecting and analyzing the data and then reworking the interview as necessary to achieve clarity and validity in its content and structure. For example, the following questions were removed after the second interview: "People sometimes talk about clouds having a silver lining - about how good things can sometimes result from the most difficult of experiences. Was there any silver lining to your experience of depression or 
the difficulties you had parenting in the year after your child came? Did anything good come of these challenging experiences?" These questions were deleted because they did not effectively "tone down" the interview, as intended. To the contrary, these questions appeared to make one participant, Mark, think more negatively about his situation and his experience of depression. In subsequent interviews, I asked participants, "What are you looking forward to experiencing with your child(ren)?" a question that successfully elicited positive comments, such as making memories with their children. Focusing on this this question allowed the interview to end on a positive and lighter note.

All participants kept the doors of communication open after their interviews by offering assistance in answering follow-up questions that arose during data analysis. Many also vocalized how they were encouraged by this research as they learned that other fathers experienced depression associated with having or adopting their children. Further, many participants mentioned that they were happy to take part in this study as it extended existing knowledge on the topic of fathers' experiences of depression, and all were interested in reading the final document. Participation in this study also had personal value for Nathan, as he emailed the following note after his interview: "It was good to talk about some things that I haven't reflected on in a while."

Paper and pencil measures. After completing the interview, participants were asked to complete a sheet with questions about their demographic characteristics (i.e., age, marital status, number of children, education, occupation, and partner's education and occupation, if applicable), shown in Appendix A. This demographic information was used to inform the analysis of each participant's data and to describe the characteristics of the sample. 
Participants were also asked to complete the Edinburgh Postnatal Depression Scale (EPDS; Cox et al., 1987), ${ }^{8}$ a five minute self-report measure of postnatal depression (see Appendix A). This measure was included so that the characteristics of the participants in this research could be compared with those of the samples used in other studies, thereby facilitating the comparison of findings across studies and people's ability to assess the transferability (Morrow, 2005) of the findings. In the EPDS participants used 4-point scales ranging from No, not at all (0) to Yes, most of the time (3) to rate how often they have experienced each of 10 symptoms associated with postpartum depression (e.g., I have been so unhappy that I have difficulty sleeping). The maximum score on the EPDS is 30, with scores of 10 or more indicating possible depression, and scores greater than 12 or 13 indicating that a participant is suffering from "a depressive illness of varying severity" (Cox, et al., 1987, p. 7).

Researchers have also found that, after appropriate modifications, the EPDS is a reliable and valid screening instrument for both paternal postpartum depression (Ballard \& Davies, 1996; Matthey et al., 2001) and post-adoption depression (Payne et al., 2010). When used with fathers, researchers recommend using a two-point lower cut-off score as indication of PPD (Matthey et al., 2001). This is suggested because Matthey et al. found gender differences in item endorsement when validating the use of the EPDS for men. For example, they found that men were less likely to report crying behaviour (one item in the EPDS) than women, and theorized that men expressed their unhappiness in other

\footnotetext{
${ }^{8}$ The EPDS was completed after the interview so as not to influence participants' responses during the interview.
} 
ways not addressed by the measure. Therefore, a score of 10 for men in the current study was indicative of paternal postpartum depression. ${ }^{9}$

The EPDS has been found to be a valid and reliable measure of depression during pregnancy and within the first postpartum year (Matthey et al., 2001). Using data from 60 women identified by home health visitors as depressed, ${ }^{10} 12$ women who were not depressed, and 12 women subsequently recruited from a local health centre whose depression status was not provided, Cox et al. (1987) found that the EPDS had satisfactory sensitivity (the proportion of depressed participants who were true positives, $86 \%$ ) and specificity (the proportion of nondepressed participants who were true negatives, 78\%). In addition, the positive predictive value of the EPDS (i.e., the proportion of depressed participants above the 12/13 threshold on the EPDS who met Research Diagnostic Criteria, a collection of psychiatric diagnostic criteria for depression) was $73 \%$, the split-half reliability was .88 and the standardized $\alpha$-coefficient was .87. ${ }^{11}$ Note, however, that Cox et al. (1987) and others (e.g., Senecky, 2009) have found that reducing the EPDS cut-off value from 12/13 to 10 provides a more accurate assessment of postpartum depression in mothers in that it increases the sensitivity of the EPDS to 84 to $100 \%$ and its specificity to 82 to $88 \%$. However, when assessing the use

\footnotetext{
${ }^{9}$ Because the EPDS is not clinically validated, participants with such scores should be assessed by a medical professional.

${ }^{10}$ These women were involved in a study exploring the effectiveness of counselling in the treatment of PPD. The home health visitors rated mothers as "normal, depressed, or having problems" (Cox, et al., 1987, p. 783), and the scale was used to confirm the suspected diagnosis.

${ }^{11}$ When the analysis was conducted using data of only those participants whom the health visitors identified as being depressed $(n=60)$, the sensitivity was $85 \%$, specificity was $77 \%$, and the positive predictive value rose to $83 \%$.
} 
of the EPDS with fathers, researchers found a score of 10 to reliably indicate PPD in their sample of 192 men at 7 weeks postpartum (this was confirmed by conducting structural clinical interviews with participants in addition to the completion of the EPDS; Edmondson, Psychogiou, Vlachos, Netsi, \& Ramchandani, 2010). Therefore, as previously mentioned, a score of 10 was considered indicative of paternal PPD in the current study.

Cox et al. also found that the EPDS was sensitive to the changes in the severity of these women's depression over time. This was established by comparing participants' EPDS scores from the initial interview ( $M$ age of infant $=3$ mos.) with scores obtained at a follow-up interview 11 weeks later. Specifically, while there was no difference in the EPDS scores of those who were depressed at both interviews $(n=15)$, there was a significant reduction in the EPDS scores of those who were depressed at the first but not the second interview $(n=16)$ (Cox et al., 1987).

Additional evidence of the validity of the EPDS comes from Harris and colleagues' (1989) comparison of the ability of the EPDS and the Beck Depression Inventory (BDI; Beck et al., 1961) to screen for postpartum depression. Analyzing data provided by a sample of 147 postpartum women, these researchers found that the EPDS had a sensitivity of $95 \%$ and specificity of $93 \%$, while the BDI had a markedly lower sensitivity of $68 \%$ and specificity of $88 \%$.

When validating the use of the EPDS to screen for postpartum depression in men, Matthey et al. (2001) found a correlation of .62 between 213 men's scores on the EPDS and the CES-D, a self-report scale designed to measure depressive symptoms in the general population (Radloff, 1977). In regard to reliability, Chronbach's alpha for the 
EPDS was .81, close to the standardized alpha of .87 obtained for women by Cox et al. (1987). Further, when completed by fathers, the split-half reliability for the EPDS was .78 , again comparable to the .88 obtained when completed by mothers (Cox et al., 1987). Matthey and colleagues (2001) also note that two EPDS items, specifically those assessing crying behaviour and self-harm, had the lowest item-total correlations (.30 and .24 , respectively), and the remaining items on the EPDS had item-total correlations ranging from .44 to .65 . Being validated for its use with men, the EPDS has been used in the majority of studies assessing postpartum depression in fathers (Deater-Deckard, et al., 1998; Edhborg, 2008; Goodman, 2008; Ramchandani, O’Connor, Heron, Murray, \& Evans, 2008; Schumacher, Zubaran, \& White, 2008).

The wording of the EPDS used in this study was slightly modified to be appropriate for biological and adoptive fathers living in Canada. In addition, the questions asked about mood symptoms during the first year after having/adopting the baby/child, as opposed to the past 7 days (Payne, 2010).

After completing the EPDS the participants were debriefed both verbally and in writing (see Appendix A). This debriefing provided information about the purpose and goals of the study as well as contact information for researcher and faculty advisor, concerns regarding ethics related issues, any other concerns, and support services available to them. After answering any questions and addressing any concerns, participants were given $\$ 20$ for their time and effort, as well as a thank you card.

Post-interview comment sheet. After leaving the interview site, I completed the post-interview comment sheet that appears in Appendix A. On this sheet I commented on things that mighty facilitate my analysis of the interview, such as my impressions of 
the participant, the mood/tone of the interview, the participant's reactions to the interview, and my own reactions to participant's responses. For example, because I was intrigued that George almost always referred to his adopted daughter as "the child" rather than "my daughter" or "my child" I noted this observation on the post-interview comment sheet. This information subsequently facilitated my analysis of his transcript where a major recurring theme was his difficulty forming an attachment to his daughter. I used my notation on the comment sheet as confirmation that I was on the right track with one of the most salient themes identified in George's transcript.

I also noted things on the post-interview comment sheet that could help improve subsequent interviews, including the mood/tone of the interview, as well as strengths and weaknesses. For example, although Charles was a single father and the primary caregiver of his two children, he was also employed fulltime. On the background questionnaire one of the questions asked about the participants' previous occupation. Unfortunately, the way this question was worded assumed that participants were primary caregivers and therefore unemployed. There were also questions asking about participants' partners' occupation, and highest level of education. I was embarrassed that these questions reflected my assumption that primary caregiving participants were unemployed and had partners. Therefore, on the post-interview comment sheet I noted the need to change the wording of each of these questions before conducting more interviews. For subsequent interviews, the questions read "Your occupation (if applicable)", "Your partner's occupation (if applicable)", and "Your partner's highest level of education (if applicable)." The ultimate reason for making these changes was to prevent future participants from feeling uncomfortable. 


\section{Participants}

Purposive sampling (Morse, 1991) recruited 4 biological and 3 adoptive fathers. ${ }^{12}$ I had intended to recruit participants until theoretical sufficiency was achieved. That is, until the identified themes sufficiently captured what was going on in the data without needing to be changed or extended when new data was introduced (Dey, 1999). However the strict recruitment criteria made it difficult for me to gather a larger number of participants within the time constraints of my program requirements. However, theoretical sufficiency was not far from being achieved. Rather than identifying entirely new themes when analyzing the sixth (adoptive father Mathieu) and seventh interviews (biological father Derek), I was simply fleshing out the nature of some of the already established themes. For example, Mathieu's data provided a deeper understanding of the pre-existing theme regarding the Importance of connecting with children. Similarly, Derek's interview data added to my understanding of a theme regarding Perceived social support.

As shown in Table 2, there was reasonable diversity in participants' demographic characteristics. Specifically, the four biological and three adoptive fathers were between 34 and 62 years of age $(M$ age $=43$ years $)$, their education varied from having completed grade nine to having a graduate degree, and their marital status included being single, widowed, living common law, being married, and being divorced. Participants had

\footnotetext{
${ }^{12}$ Although Henry and Mathieu participated in this study as adoptive fathers, both were fathers before the adoptions. Before adopting his daughter, Henry was step-father to a young boy. After the adoption he now refers to himself as being a "direct parent," whereas before he was not. Prior to adopting his young daughter and son, Mathieu was a biological father to two teenage girls.
} 
between one and four children. The time since having their child associated with the depression episode 
Table 2

Participants' Demographic Characteristics

\begin{tabular}{|c|c|c|c|c|c|c|c|}
\hline $\begin{array}{l}\text { Type of } \\
\text { father }\end{array}$ & Pseudonym & Age & Ethnicity & Education & $\begin{array}{l}\text { Martial } \\
\text { status }\end{array}$ & $\begin{array}{l}\text { Number of } \\
\text { children (ages) }\end{array}$ & $\begin{array}{l}\text { Time since having } \\
\text { or adopting child }\end{array}$ \\
\hline \multirow[t]{3}{*}{ Adoptive } & George & 62 & $\begin{array}{l}\text { Swiss- } \\
\text { German }\end{array}$ & $\begin{array}{c}\text { Undergraduate } \\
\text { degree }\end{array}$ & Married & $1(14)$ & 4 months \\
\hline & Henry & 34 & $\begin{array}{c}\text { Caucasian- } \\
\text { British }\end{array}$ & BA & Married & $\begin{array}{l}1 \text { adopted (2.5) } \\
\text { I step-son (13) }\end{array}$ & 1 year \\
\hline & Mathieu & 39 & $\begin{array}{l}\text { French- } \\
\text { Acadian }\end{array}$ & Grade 10 & $\begin{array}{l}\text { Common } \\
\text { law }\end{array}$ & $\begin{array}{c}2 \text { adopted }(5,6) \\
2 \text { biological }(18,19)\end{array}$ & 5 years \\
\hline \multirow[t]{4}{*}{ Biological } & Mark & 52 & Polish & Grade 9 & Single & $3(13,22,28)$ & 13 years \\
\hline & Charles & 42 & Caucasian & $\begin{array}{l}\text { Graduate } \\
\text { degree }\end{array}$ & Divorced & $2(3,6)$ & 3 years \\
\hline & Nathan & 35 & $\begin{array}{c}\text { White } \\
\text { European }\end{array}$ & $\begin{array}{l}\text { Graduate } \\
\text { degree }\end{array}$ & Married & $2(6,7.5)$ & 6 years \\
\hline & Derek & 38 & Caucasian & $\begin{array}{c}\text { Undergraduate } \\
\text { degree }\end{array}$ & Widowed & $1(9)$ & 9 years \\
\hline
\end{tabular}


Table 2

Participants' Demographic Characteristics Continued

\begin{tabular}{|c|c|c|c|c|}
\hline $\begin{array}{l}\text { Type of } \\
\text { father }\end{array}$ & Pseudonym & $\begin{array}{l}\text { Participant's occupation } \\
\text { (if applicable) }\end{array}$ & $\begin{array}{l}\text { Partner's education } \\
\text { (if applicable) }\end{array}$ & $\begin{array}{l}\text { Partner's occupation } \\
\text { (if applicable) }\end{array}$ \\
\hline \multirow[t]{3}{*}{ Adoptive } & George & Construction/design & University & Policy analyst \\
\hline & Henry & $\begin{array}{l}\text { Television commercial } \\
\text { producer }\end{array}$ & Undergraduate degree & Civil servant-training \\
\hline & Mathieu & Construction & Grade 12 & Unemployed \\
\hline \multirow[t]{4}{*}{ Biological } & Mark & Mechanic & $\mathrm{N} / \mathrm{A}$ & $\mathrm{N} / \mathrm{A}$ \\
\hline & Charles & Process scientist & $\mathrm{N} / \mathrm{A}$ & $\mathrm{N} / \mathrm{A}$ \\
\hline & Nathan & Professor $^{13}$ & Undergraduate degree & Full-time mother \\
\hline & Derek & Surveillance supervisor & $\mathrm{N} / \mathrm{A}$ & N/A \\
\hline
\end{tabular}

\footnotetext{
${ }^{13}$ Although Nathan is currently employed as a professor and his partner is the primary caregiver of their two daughters, Nathan discussed his experience being a primary caregiver after taking an extended parental leave five years ago.
} 
discussed during the interview ranged from four months to five years for the adoptive fathers and from three months ${ }^{14}$ to 13 years for the biological fathers. In contrast to the diversity in these attributes, there was little variability in participants' ethnicity as all of the fathers were from central European, British, or French Acadian descent. ${ }^{15}$

Table 3 provides information about participants' experiences with depression. As shown there, participants' EPDS scores ranged from 3 to $20(M=14)$, suggesting all but one participant experienced postpartum depression in the 12 months after having or adopting their child. ${ }^{16}$ Given this, the purposive sampling for primary caregiving fathers who had experienced depression within 12 months of having or adopting a child appears to have been successful in all but one case. This one case, Derek, was due to a misunderstanding regarding the study's participation criteria. In addition, all of the participants had experienced depression at least once prior to having or adopting their child and all but two participants had received a formal diagnosis for their depression.

Participants became primary caregivers for a variety of reasons. Among the adoptive fathers, George described himself and his partner as both being the primary caregivers of their adopted daughter, though his responsibilities peak when she returns

14 Charles, a biological father of two children (who were three and six years of age) did not become depressed when either of his children was born. Instead, his depression began when he became a single parent and the primary caregiver of his children three months before the interview.

15 The information regarding participants' ethnicity is taken verbatim from the participants' self-descriptions. Although it is debatable whether Caucasian is an ethnicity (i.e., some consider it to be a race), I regarded it as inappropriate for me to impose a label on them.

${ }^{16}$ EPDS scores $\geq 10$ indicated that a participant had experienced a "depressive illness of varying severity" (Cox, et. al., 1987). 
Table 3

Participants' Current and Earlier Experiences of Depression

\begin{tabular}{lcccc}
\hline $\begin{array}{l}\text { Type of } \\
\text { father }\end{array}$ & Pseudonym & $\begin{array}{c}\text { EPDS } \\
\text { score }\end{array}$ & $\begin{array}{c}\text { Prior experiences } \\
\text { of depression* }\end{array}$ & $\begin{array}{c}\text { Formally diagnosed } \\
\text { with depression }\end{array}$ \\
\hline Adoptive & George & 17 & Several times & Yes \\
& Henry & 14 & Once & No \\
& Mathieu & 19 & Several times & Yes \\
Biological & Mark & 20 & Several times & Yes \\
& Charles & 10 & Once & No \\
& Nathan & 17 & Several times & Yes \\
& Derek & 3 & Never & No \\
\hline
\end{tabular}

* Response options for this question were No, Once, Twice, and Several times. 
home from school until she falls asleep. Henry became primary caregiver of his adoptive daughter after losing his fulltime job. Mathieu became primary caregiver of his two adoptive children since his partner (the children's biological mother) was not taking an active role in parenting the children. Of the biological fathers, Mark was the primary caregiver of his three daughters at different stages and for different periods of time during their childhoods. His focus during the interview was on his role as primary caregiver of his youngest daughter, Megan. He became Megan's primary caregiver when his partner began neglecting Megan as an infant and then left him. Charles became primary caregiver to his two young children after divorcing his partner. Charles and his partner share custody of their children and live in two separate households. Nathan and his partner shared the role of primary caregiver when his first daughter was born, however Nathan became the primary caregiver when their second daughter was born and his partner worked fulltime. Lastly, Derek and his partner shared the caregiver role for their son; however, after his partner committed suicide, Derek became the sole primary caregiver.

\section{Analysis}

A thematic analysis of the transcribed interview data was conducted as it is a method consistent with the constructivist paradigm (Ponterotto, 2005) guiding this research and allowed me to analyze the data in a way that would answer the research questions. As Braun and Clarke (2008) note, a thematic analysis is "a method for identifying, analysing and reporting patterns (themes) within data. It minimally organizes and describes your data set in (rich) detail” (p. 4). Elaborating on what constitutes a theme, these authors state "a theme captures something important about the 
data in relation to the research question, and represents some level of patterned response or meaning within the data set" (Braun \& Clarke, 2008, p. 7).

An inductive thematic analysis was conducted using the transcripts of participants' interviews. Although it was important that the analysis (and the subsequent identification of themes) was spurred on by the data (Braun \& Clarke, 2008), I did not disregard the themes documented in previous research on postpartum depression. Rather, I problematized them by questioning their validity and clarifying the extent to which they influenced these fathers' experiences of depression (e.g., questioning if participants had any unfulfilled expectations and, if so, whether this played a role in their depression).

Following Braun and Clarke's (2008) guidelines, I began by completely familiarizing myself with the data. This included transcribing each interview and reading each transcript multiple times. Then I completed the remaining five phases of thematic analysis outlined by Braun and Clarke, using ATLAS.ti 5.0 software. Specifically, I applied codes (i.e., brief labels) to each chunk of meaning in a transcript. I began by using low level descriptors that stayed close to the data (e.g., in vivo coding), followed by more abstract coding. In vivo codes represent actual words chosen by participants during the interview (Charmaz, 2006). ${ }^{17}$

Upon completion of coding, I created a master code list describing the nature of each code used by providing a label for each code (1-3 words), a definition of the code (describing main characteristics), a flag description of the code (e.g., how to recognize

\footnotetext{
${ }^{17}$ For example, when describing his relationship with his daughter, George stated, "I have to maintain a connection with her and I can't endure the connection with her. Because it's so draining and because it's so intrusive on me." The in vivo code representing this was "it's so draining."
} 
code when it is present and when code should be applied to text), any exclusions or qualifications (e.g., when the code should not be used), and one or two examples of text that has been coded using each code.

In addition, I organized codes, noting when codes co-occurred or overlapped and the relationships between codes. Next, I searched for themes and subthemes in the data by considering how the codes combined to create a theme (Braun \& Clarke, 2006).

In order to ensure clarity in the themes identified during analysis, I refined themes by clearly naming and defining each one. For example, it is possible that two separate themes can collapse into each other, creating one new theme. It is also important to revisit the appropriateness of all themes throughout the analysis. While completing this step I found that the following theme: society's influence on experiences of depression, was too large to be adequately represented within the section of results on shared aspects of primary care-giving biological and adoptive fathers' experiences of depression. For example, this theme had a large number of detailed subthemes that would not have been adequately represented had this theme been left in this section. Therefore, because this theme captured such significant details of participants' experiences of depression, it seemed appropriate to make the theme a section in and of itself; which accurately reflected the depth and detail it deserved.

Following the final phase of the thematic analysis, I produced a concise and coherent written report featuring the themes resulting from analysis, including appropriate examples extracted from participants' transcripts (Braun \& Clarke, 2008). ${ }^{18}$

\footnotetext{
${ }^{18}$ The authors also offer a checklist of criteria for a good quality thematic analysis. This was consulted throughout the entire process of analysis (See Braun \& Clark, 2008, p. 21).
} 
In addition, participants' EPDS scores were calculated for descriptive purposes. Given the small sample size, participants' EPDS scores were not subjected to an item analysis.

Efforts to enhance research quality. Although there is much debate regarding the criteria that should be used to evaluate the trustworthiness or rigour of qualitative research, and even whether they should be any criteria at all, some (e.g., Morrow, 2005) suggest using four criteria, namely credibility, dependability, confirmability, and transferability. Credibility refers to the rigour of the research process and, as a result, the trustworthiness of the findings (Morrow, 2005). There are many ways of facilitating research credibility, some of which were used in this study. In particular, I used diverse recruitment strategies to ensure that different experiences and views were represented in the data and the EPDS provided evidence that I sampled members of the population of interest. In addition, the in-depth interviews consisted of open-ended questions and I encouraged depth and detail in participants' responses by using probes and follow-up questions. Added to this, the interview guide was iteratively reworked to ensure that the questions were understood as intended and addressed the interests that emerged during the course of the analysis. Finally, to further enhance the credibility of this research, I sent each participant a copy of their interview transcript prior to data analysis and encouraged them to make additions, deletions, clarifications, or elaborations to their data (i.e., I conducted members checks; Morrow, 2005). Doing this provided an additional opportunity to increase the clarity, depth and breadth of the data. It also gave the participants some power over their data and hopefully facilitated their comfort with what they disclosed. All but two participants provided feedback for the member check. 
Dependability refers to the reliability or consistency of the research process, as well as its replicability. To facilitate the dependability of the study I recorded all of my methodological decisions (e.g., regarding study design, study execution, sampling, and changes to interview questions) in a methods journal. Similarly, while I analyzed the data I recorded my analytic thoughts and decisions in memos, thereby documenting the way codes evolved. As Birks, Chapman, and Francis (2008) state, memoing is also beneficial as it allows researchers to "articulate, explore, contemplate and challenge their interpretations when examining the data" (p. 71). Added to this, memoing provided space for me to alter and consolidate codes to eliminate redundancy and enhance clarity (e.g., merging the code "difficult behaviour of child" with the pre-existing code "undesirable behaviour of child"). It also helped me code the data consistently throughout the analysis. Together, this documentation comprises an audit trail and is available to anyone who might want to replicate the study.

Good qualitative research should be confirmable in that its findings are driven by the data rather than beliefs or biases of the researcher (Morrow, 2005). I believe keeping a personal self-reflexive journal contributes to the confirmability of these findings as doing so facilitated my mindfulness of my personal opinions and beliefs regarding postpartum depression (Morrow, 2005). Providing sufficient participant quotes in the results that follow should go some way to allowing readers to judge the groundedness of my interpretations, as may the information about my own standpoint that appears in my researcher-as-instrument statement.

Finally, transferability refers to the "extent to which the reader is able to generalize the findings of a study to her or his own context” (Morrow, 2005, p. 252). My 
researcher-as-instrument statement along with the information about the sampling methods, the characteristics of the participants, the research context, analysis, and the research process as a whole should facilitate the transferability of these findings (Morrow, 2005).

Researchers working from a social constructivist paradigm also endeavour to enhance the authenticity of the research project. Signs of ontological authenticity were apparent in this study in that participants appeared to develop an expanded or more sophisticated understanding of their experiences with depression. I also hope that reading the results of the study will help participants appreciate other fathers' experiences with depression. If so, this research will also have what is called "educative authenticity" (Morrow, 2005). 


\section{Results}

The analysis of the interview transcripts revealed both commonalities and differences in biological and adoptive fathers' experiences of depression. The analysis also revealed society's influence on these fathers' experiences of depression. Each of these areas was characterized by a number of themes, as displayed in the thematic map in Figure 1 and outlined below.

\section{The Nature of Fathers' Experiences of Depression}

The biological and adoptive fathers described the nature of their depression using similar terms, terms that involved feelings of loneliness, confusion, fatigue, the loss of motivation and the inability to feel pleasure. For example, Mathieu, a 39 year-old adoptive father, described his feelings by saying, "I'm lost. I'm confused and very lonely ... But I think that's why I got so unhappy in the last year because I was keeping it all inside of me." Henry, a 34 year-old adoptive father, said he experienced an extreme lack of energy and had absolutely no motivation to do any of his daily activities. As he put it, "I definitely went through bad moments of sitting there, laying on the couch face down. What's the point of getting up?" Charles, a 42 year-old biological father, not only described being fatigued, but also being unable to experience pleasure: "Just lack of will to do things, just to - you know, doing work was hard. Experiencing joyful things was

not the same." Some fathers, especially biological fathers, reported experiencing suicidal thoughts. While describing a particularly low point, Mark, a 52 year-old biological father, said: “I didn't care about anybody or anything. Uh, I almost walked off a roof that I was working on. I wanted to. And then I changed my mind at the last second." The similarity in the nature of these fathers' experiences of depression was also evident 
in the fact that all of them endorsed so many of the items measuring depression in the EPDS.

\section{Commonalities in Biological and Adoptive Fathers' Experiences of Depression}

Eight themes, listed in Figure 1, underlay the shared aspects of biological and adoptive fathers' discussions of their experiences of depression. These common themes included Significant stressors, Increased responsibilities, Profound life changes, Intense emotions, Expectations-reality asymmetry, Own understandings of depression, Perceived social support, and Importance of Connecting with their Child.

Significant stressors. All of the fathers said they experienced significant interpersonal, intrapersonal, and external stressors immediately before and during the time of their depression. For example, Charles, a 42 year-old biological father, described the financial stress he experiences providing for his children as a result of his recent divorce. Added to this stress, Charles also described feeling internally driven to care for his and his children's emotional well-being. As he put it:

There's nobody preparing you well for what the experience is going to be like. Again I think I've said it before, it's almost glossed over as to what it entails. The financial stress it causes for yourself having one income - especially in sort of an economic recession, it's very difficult. Wherever you work I talk to people, it's tough that way. There's that - running a household on one income is a huge responsibility. And then maintaining the emotional welfare for yourself and for your kids is another huge responsibility.

Mark, a 52 year-old biological father, said his depression became dramatically worse as a result of the interpersonal stressor created by the emotional and verbal abuse by his partner, Lauren. He was also deeply troubled by Lauren's neglect of their daughter, Megan, 


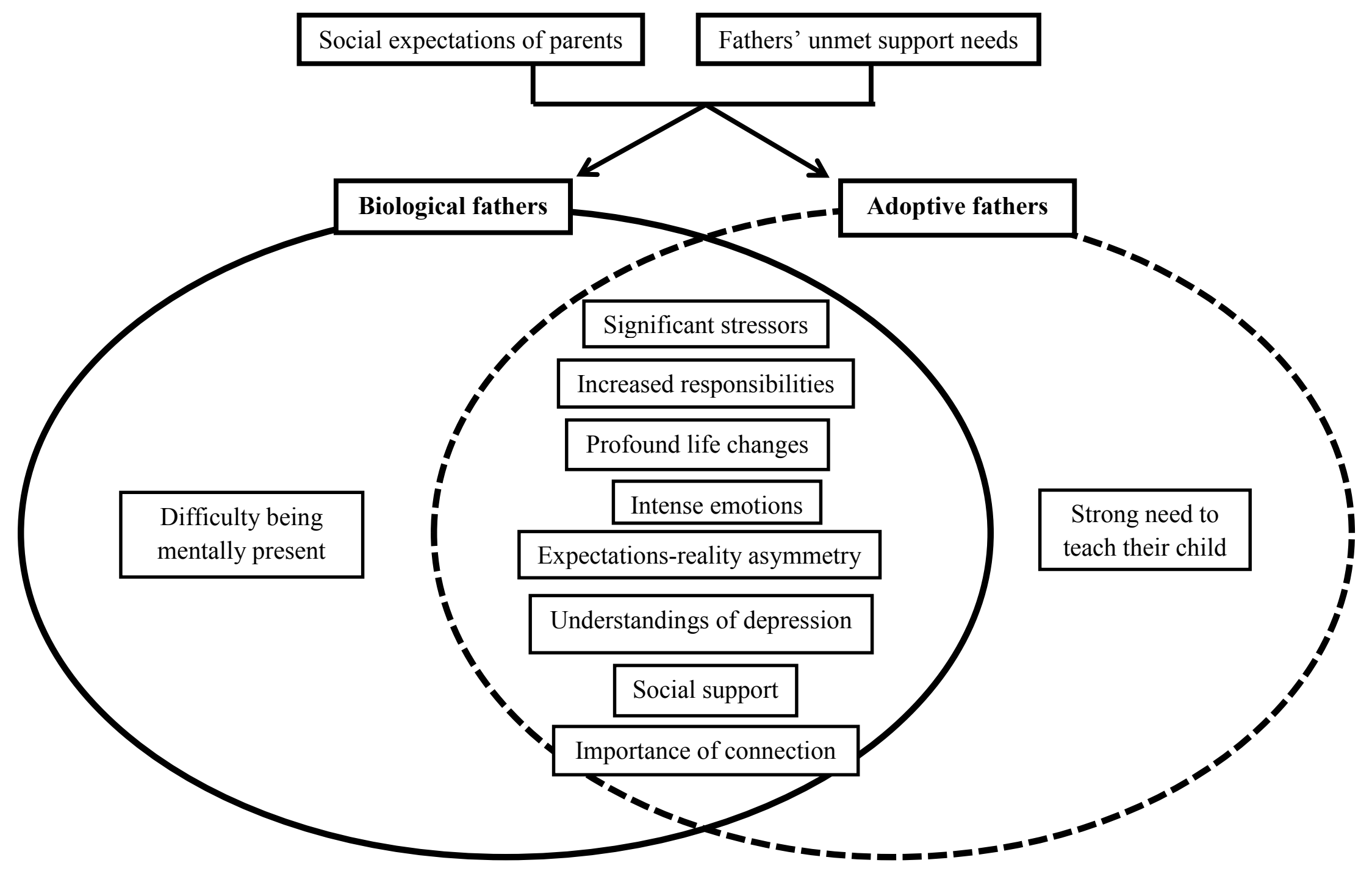

Figure 1. Themes underlying biological and adoptive fathers' experiences of depression. 
and felt responsible for ensuring Megan was taken care of. When asked about the time period in which he started feeling depressed, Mark responded by saying:

Well I was feeling bad because Megan and I were being treated so horribly. And you just can't be happy when you're hated, or when you feel hated. Lauren started bitching at me all the time. Bitchin' and bitchin' continuously until I couldn't - Megan wouldn't even eat unless I was there. You know, when she was a baby. Lauren scared the hell out of her. She was so afraid of her crib... [Lauren] was very hard on me and then she started getting very hard on Megan and she would put Megan in the crib to get her out of the way. I go home at night and I go to put Megan to bed and she was so afraid of the crib that she would shit herself. She was just a baby... So I ended up making her a little captains bed - a crib sized captain's bed so that she could get in and get out and she didn't have the bars but she couldn't fall out the sides 'cause of the rigid side.

Interestingly, Henry, a 34 year-old adoptive father, used the voluminous number of external stressors in his life (e.g., helping to care for his father who had Alzheimer's, completing all of the household chores) to distract himself from his depression. As he explained:

But a lot of time my mom is out of touch and if they call and say, "Your dad has had a bout of incontinence," I end up having to deal with that and have to sort it out and get there and pick him up, find my mom, get him home, get back in time by noon. So I have all this stress but it's preventing me from dealing with any depression. I don't know if that's always bad.

Henry's use of stressors as distractors is easily understood given his previous experience of depression. Earlier in the interview Henry said that he became depressed when, after moving to Ottawa, he was unemployed because he had difficulty securing a job in his field. Having learned from this experience that his depressive symptoms became worse 
when his mind was unoccupied, Henry is now very careful to structure his day with activities that prevent him from ruminating.

But it was much harder than expected for me to find a job once I moved here that was 2006. So I definitely went through a tough period of depression during the transition. So that was about 8 months of unemployment. There was no kid around at home it was just me. Sitting there. That was it. Looking for work, my field is generally film and television. And Ottawa is definitely not the place for that. So I really had a lot of trouble finding something I could do. So I wasn't perpetually depressed during that time, but I definitely went through bad moments of sitting there, laying on the couch face down. What's the point of getting up? And so in a lot of ways that helped me for this period in 2012 ... Although I didn't necessarily learn a lot of tools and tricks to get through it, I knew I didn't want to be there again in that situation. So I tried to get out biking and doing as much as I could - I do a lot of writing just to keep my mind occupied. Setting goals no matter how insignificant.

Increased responsibilities. Dramatic increases in their responsibility with their children also added to participants' experiences of depression. Some of these increased responsibilities began as soon as they became primary caregivers and others were longterm responsibilities that continued over time.

After adopting two young children, 39 year-old Mathieu was overwhelmed by the reality that he had to fulfill both his own responsibilities and those of the children's mother. To explain, he gave the following example.

For some reason this morning they knew I had to go somewhere - because I usually bring them to the bus stop. They both start screaming because they wanted me to bring them to the bus stop. But I said I had to go see a teacher, that's what I said. And Reid goes, "No! I don't want mommy. I want you to bring me to the bus stop, I want you to come and get me." And Jade goes, "I want you to do my hair." And then the kids start to fight. So [their mother] was 
just sitting there and I said, "Well can you help me please?" "Well," she goes, "they want you!" I understand what she means but she still has to try to help. It's putting me very depressed. Right now that's what I feel I am. I'm the mother and the father of these two kids. It's just one example.

Charles noted how the responsibilities involved in caring for his two young children increased dramatically after his divorce was finalized.

It's more responsibility. It's a higher intensity of responsibility. When you share the responsibility it's easier. There's the financial thing, which is always huge. Then there's time given to the kids, which now I have less quality time with the kids. So with two people in the house you can have one parent doing something and the other spending quality time with the kids. With one parent in the house they're doing something and not spending quality time with the kids. So it doesn't matter who's spending quality time, they are always getting quality time and involvement and now that bothers me and so I try to orchestrate my free time so I get all those responsibilities out of the way so when I'm with the kids I can give them my full attention. But I can't cook dinner and give attention to the kids at the same time.

Henry said the increase in responsibilities came as a shock after the adoption of his daughter, Ruthie, was finalized. Henry had grown accustomed to the joint custody living arrangements that were in place for his step-son, Lincoln, and had to adjust to the long-term responsibilities of full-time parenting.

So nothing was working out the way I anticipated. But that wasn't necessarily a problem, it was just everything was different. The other thing is that with Lincoln- he's with us for a week and then he's gone for a week. That's the way it's been since we got married 7 years ago now. So our marriage was always weird because of that. We had a week with Lincoln where we had to be responsible adults. Then we had a week off where we didn't have to worry about dinner time; we didn't have to worry about anything... Then we had Ruthie around and it was a tough switch. Because I kept sort of saying to myself for 
the first little while, "When is she gone to her dad's house?" And then I'd be like, "Oh god, this is the next 18 years."

Profound life changes. All of the fathers said becoming a primary-caregiver changed their focus and interrupted their routines. In addition, they said these lifestyle changes influenced or exacerbated their depression.

When asked to describe his transition to fatherhood, Nathan, a 35 year-old biological father, reflected on how caring for his newborn daughter dramatically altered his life and his focus:

I don't think I was ever fully prepared for what it was going to be like to be a parent. Both the absolute joy of it and the wonder of it and how beautiful this person is, and how absolutely exhausting and frustrating and infuriating I found myself to be at times as a result of having somebody who needed attention and care all the time. That's kind of the feelings of it. It changes everything. It changed everything about life. I think I've always been career and work and goal oriented and focused. And I learned quickly and recognized quickly that little people require so much love and care and attention that I had to kind of reorient myself.

George, a 62 year-old adoptive father, said his depression started after he adopted a teenage girl with significant behavioural and emotional issues and that it became worse as a result of the profound disruption of his everyday routine. In particular, because his daughter required constant supervision, he had to put the construction activities he loved doing on hold.

So there's a lot of stuff that I want to get going at and really dealing with Sara and the adoption transition, I've hardly done anything on the house in 5 months. And that to me takes away my craft. I'm not doing what I do. 
Intense emotions. All of the fathers reported frequently experiencing intense emotions during their period of depression, emotional states that were characterized by feelings of helplessness, hopelessness, and being completely overwhelmed. In addition, all of the fathers reported feeling anger.

When asked about his experience of depression, Nathan described how his daughter's temper tantrums left him feeling helpless in that he did not know what to do or how to respond to her. He said:

The thing that really triggered my own frustration and anger was temper tantrums with children. I found those completely overwhelming and didn't know how to handle them ... But I felt really overwhelmed a lot of times with lack of sleep and all that ... I think it heightened the depression in the sense that I felt that I couldn't handle it, and didn't know what to do about it.

Similarly, George reported feeling hopeless about his relationship with his daughter, Sara. Having reached a point where he was emotionally drained and tired of devoting so much of his time, energy, and thoughts to his daughter, George seemed to have given up on things getting better with Sara. As he put it: My confidence is really up and down. Right now it's really low because I have ... I've been doing an extrusion of Sara. I want her out of my life. It's uh, yeah, it's like she's in my face way too much. And I just want to be - I go to bed thinking about her, I wake up thinking about her and what to do and part of its just survival. It's desperation. I cannot - this is a four month immersion. And I don't see it getting better.

When asked about social support, Nathan said his partner and his brothers were supportive during his experience of depression. In addition, however, Nathan also described his brothers' transitions to fatherhood as characterized by depression and feelings of being overwhelmed. 
Yeah, and I think that was another reason why I was intrigued with your study because observing [my brothers], it's all really been since we've become parents where we've each experienced coming apart at the seams a little bit. I mean, I definitely got off the rails depression wise and needed help. And each of them too, it's been a lot around becoming parents. I mean they've had different challenges - one brother had a really colicky baby, and he and his wife have since split up. Like it really destroyed them. And I mean they're both working hard to be good parents, but that was so hard for them.

In addition to experiencing intense feelings of helplessness, hopelessness, and being completely overwhelmed, all of which are typical of depression, these fathers also reported experiences of intense anger. For example, in a follow-up email after the interview, Henry described how a recent chaotic situation involving his wife, his daughter Ruthie, and his step-son Lincoln, that completely overwhelmed him left him quite angry:

On Monday I was losing my mind over how messy the house was. [My wife] left for work without putting the iron and ironing board away and I couldn't get into the laundry room to clean the towels I used after the dog peed on the carpet because the ironing board was in the way. So the iron fell on the floor and leaked water everywhere. But I thought it was more dog pee so I blamed the dog. Lincoln also hadn't put his laptop away like I've asked him too many times. The whole day was off to a bad start because Ruthie snuck out of bed Sunday night, found a black sharpie and decorated the door to the linen closet. Anyway ... the point to all this is that I was losing my mind and told [my wife] and Lincoln how mad I was ... My most important point being that I am a stay at home dad for Ruthie - to help her grow and help her keep up and so on. Just because I'm at home more doesn't give them an excuse to be less clean. Also, I personally feel that they need to be more clean because now the house is my "work space."

Interestingly, such experiences of anger were especially true for the participants 
who had experienced emotional, physical, and/or sexual abuse during their own childhood. Nathan, for example, grew up in an abusive household and described his father as a "terrorizer" and a "tyrant." During the interview he recalled his own angry reaction to his daughter's temper tantrum, saying:

I still have a clear picture. Especially one day where my daughter was having a temper tantrum upstairs and my wife was downstairs. I was trying to get her ready for bed and I had to get out. So I ran down the stairs and I literally started punching myself in the face. I was hitting myself and had to get out, went out for a walk, and on top of that - during that time I had severe, significant suicidal thoughts too. Just wanting to - I would walk to my work and I just wanted to kind of throw myself into traffic at that point.

George's childhood was also ridden with abuse. Between the ages of eight and fourteen, he was sexually and emotionally abused by a priest, an experience he described as a "mind fuck" because after abusing him the priest would make him confess his "sins." George was also physically and emotionally abused by his mother. Here, George describes how he responds with anger to his daughter's undesirable behaviour.

So then I used - I would have blow-ups. And that's come up at times. It's like my reaction to depression is usually contained, withdrawn. And then I'll come out of it sometimes with tremendous energy. And, um, so anger is one way which - that's the one I'm really dealing with now. Is to - I need to walk away from her ... And yet, sometimes I just lose it. I haven't hit her. Um, but I started coming to a point where uh it's ...

Expectations-reality asymmetry. The asymmetry between participants' expectations and the realities of their lives after having or adopting a child was full of complexities. This lack of symmetry pertained to a diverse range of things, including the 
behaviour of their child, the time and energy caregiving required, the attachment between parent and child, and the domestic responsibilities of one's partner.

When asked what made him decide to participate in this study, George described how his erroneous pre-adoption expectations of his 14-year-old daughter's behaviour contributed to his depression:

I kind of hit bottom 2 or 3 weeks ago. With the, um, our child's been with us, she's fourteen, and she's been with us for four months now and, um, it's a lot to do with I think expectations. Expectations and seeing also the child that we saw, it was a three month transition period of us visiting her, and her visiting us. She's from [city B]. And, uh, the child that we saw is not the child that we got. I mean there is that thing where the child presents her best side. And she's been a real handful. Much to everybody's surprise, how difficult she can be ... I think three weeks ago I just sort of gave up. Um, that she's not everything I thought about having a daughter. It's not going to happen ... Also let me grieve, let me mourn, let me lose the expectations because I need to burn them out. And then come down to nothing and then see ok I know that I honour my commitment [of being Sara's father].

When asked if he had any expectations about being a primary caregiver, Nathan spontaneously commented on the unrealistic nature of his expectations regarding the amount of work and time he would have to dedicate to his newborn daughter. He explained:

Nathan: I think it was way more work than I actually imagined it would be. I think I was mostly excited beforehand about it, but I also didn't realize how exhausting it would be. And I sort of had this vision of being by the lake [up North] and my kids are hanging out and -

Interviewer: Playing in the sand. 
Nathan: $\quad$ Yeah and the water- exactly! And there was some of that for sure. But it was mostly about caregiving and taking care of them and trying to get them for naps and changing them and all that kind of stuff. Yeah so trying to structure their routine and then realizing that there are not many breaks for young parents. That it's all the time. Even stuff like when do I shower? When do I sit down and read a book. That kind of stuff doesn't really happen.

Only Mark and Charles did not provide detailed descriptions of how their expectations did not measure up with reality. In Mark's case the volatility of the relationship with his partner, Lauren, and the strained family dynamics left him too preoccupied with worry to develop any expectations about becoming a primary caregiver to his daughter. Instead, Mark's focus was on protecting Megan from her mother's emotional abuse and neglect. Charles, on the other hand, felt entirely unprepared for becoming a primary caregiver and, as a result, did not know what to expect. As he put it:

So you almost feel like, "What are my expectations?" Well, it's hard to know because it's never described what it's going to be like. So you break a leg and it's like, "Well, it's gonna hurt and you'll have a cast on and you'll have the cast for four months" - it's very simple. And the doctors and the nurses prepare you for it. And there are outpatient resources to support that. OHIP pays for that right! But here, which is probably much worse than a broken leg, what's there? They don't prepare you for it. So what are your expectations? You don't know. You can have whatever expectation you want, it's meaningless almost. Are my kids going to be alright and am I going to be alright? Yes, but is everything hunky dory and fine? No.

Own understandings of depression. Some of the fathers offered explanations of the causes of their depression. Adoptive father George explained how his daughter contributed to his depression: 
That's where I think a part of my depression comes from. I'm trapped. I can't get away from it. I have to maintain a connection with her and I can't endure the connection with her, uh, because it's so draining and because it's so intrusive on me.

Charles became the primary caregiver to his young son and daughter as the result of divorce. During the divorce process, Charles believed that he was the only one whose primary focus was on the well-being of his children, and he attributed his depression to this sense of being alone with an overwhelming responsibility:

And that's why I get depressed. So you want to talk about depression, that's why I'm depressed. They [the family law system] don't focus on the kids. So, that's the tough part. And nobody's there for the kids so I have to step up. And that's a huge responsibility. I almost feel like I take all of that on my shoulders. In a world where the resources don't exist or where they're not really there. It's almost like you're fighting through a cloud on the whole thing. So it's tough, it's very tough.

Perceived social support. Most participants discussed having significant sources of social support, including friends, family members, an adoption support worker, a Child and Youth Worker, a Child Psychologist, and family doctors. Biological father Nathan, for example, was quick to discuss the phenomenal support he received from his motherin-law and family doctor:

[My wife] has a super mom, who is super grandma, and she's always available. And she's one of those people that does it all for her family. And so we've had great support from her ... I was lucky too because my family doctor is somebody who does counselling on the side. He does one day a week of counselling and so, literally in talking to him for 10 minutes, I felt like he understood where I was coming from and he really understood the connections between depression and [my own experiences of] early childhood trauma. 
Adoptive father George described the support he and his partner receive from an adoption support worker and a child and youth worker as fundamental in helping him deal with the difficult adjustment period following the adoption of his daughter Sarah. He said:

We have our adoption worker and we have a child and youth worker who has been assigned. And they work only with us, they don't work with Sarah. And they've been very good with their times. We can have them over once a week and they stay for two or three hours and we just talk. My wife and I a lot of times we just vent of the behaviours and how difficult it is to endure [Sarah's] behaviours. Trying to get some perspective on [Sarah's] behaviours.

When asked if there was anything that made him feel better during his experience of depression, Charles, a biological father of two, pointed to his supportive friends and family. However, the practical or instrumental support he needed from them was inconsistent.

They [friends and family members] were supportive. Absolutely supportive. They said, "Anytime you need help" and that type of thing. Um, emotionally supportive, financially supportive, their own time supportive. I do have great friends and family who are supportive. But in the real time of things, you know I just can't call somebody up and say, "Can you babysit? I have to do this ..." It's almost impossible. People have their own lives so you're in a very stuck situation.

Although Henry had the support of his family, he said that he rarely asked for or needed help. Interestingly, he justified his behaviour by referring to the masculine gender role expectations:

No, that's probably my own personality though in that I naturally have an inclination to not ask for help with things. I don't want to say it's as severe as I 
see it as a sign of weakness when people ask for help but, you know, it could be a male ego thing, I'm not quite sure. But I don't like asking people for help or for things. I feel more comfortable asking a child for help probably than an adult because maybe I can sort of excuse it as when I ask a child for help I'm teaching them to be helpful. And adults - maybe it's like I said - it is pride, not only that I feel like maybe I'm in debt to them, but also they might look stronger than me if I need their help.

Importance of connection with their child. All six fathers described the importance of developing and maintaining a connection with their children. After his divorce, biological father Charles felt extremely depressed by his perception that he was alone in supporting his children and protecting their emotional welfare. However, during the interview his face brightened and his tone lightened substantially when he discussed the supportive foundation he was building for his children.

You know, I'm trying to make them feel like they have a foundation somewhere. For me that's - so they don't feel like they're lost ... Make them feel at home; somewhere where they feel connected. They will always have some fast hold in their life which is supportive. So they're going to be part of that process and I'm looking forward to that too.

When describing the life events contributing to this depression, Mark's narrative was chockfull of broken relationships, substance abuse, poverty, and homelessness. Although his voice and body language were strained by the weight of these experiences, his outlook became instantly brighter when he began discussing his relationship with youngest daughter, Megan. Mark provided vivid example of the importance of maintaining a strong connection with his child when he said the following: 
Mark: Megan was the most important. Has always been the most important. She's number one on my list.

Interviewer: Yes, it sounded like you had quite the bond with her when she was little.

Mark: $\quad$ There's no had. It's have.

Nathan, a 35 year-old biological father, also spoke of the importance of nurturing a connection with his daughters from birth, this time within the context of being asked if he had any expectations about becoming a primary caregiver. He said:

I think the main hope was for some kind of connection with my children. I think I sort of have - I really want to know and understand my children and who they are. So I was just hopeful for - I mean obviously both of them are really young at that point, but still being able to connect with them. My hope was just to kind of be with them and be able to play with them and be there for what they needed.

Mathieu described how having his two adoptive children attach to him significantly relieved his symptoms of depression.

I was feeling great because I could see how happy the kids are with me. Like Jade, she knows I'm not her real dad. But for me, all I could see was the happiness of the kids. I could be gone for just an hour - and I had a big window, and when I pulled in with the car I could see them and it was like I had a trunk full of toys, but I didn't. They didn't care about toys. They did not. My kids do not care about toys. The only thing they care about is me.

Although attachment is celebrated, especially following an adoption, Mathieu appeared to have become rather dependent on his attachment to his adopted children. Mathieu described his depressive symptoms, stress and anxiety as peaking at night after his children had gone to bed. He also said that the only way he has any relief from the 
physical ailments associated with his stress and depression and is able to fall asleep is when his son is sleeping beside him.

It's bizarre. In the last couple months, my stress, my 'down' comes at night ... It's so bizarre, like seriously I'm freaking out. I don't know if I'm getting sick because my heart burn comes, my depression - I'll start thinking about that about 10:05 every night, then at 10:45 I get big heart burn. It's been going on for a few months. And that's when I crawl and I go to sleep beside him ... And sometimes it's so bad that I wake him up. I open the door before I lay down and I wake him up. Why am I doing that? Why? Then he gets up and he's cranky for a minute because he wants to sleep, then he goes, "Okay daddy, sleep in my bed." And it's a race car bed and its small, right, so I put a big pad on the floor, wake him right up at 11:00 and he comes with me and then I fall asleep. Sometimes I wonder why. But the kids make me happy.

While developing and maintaining an inward connection with their children was very important fathers, maintaining a noticeable outward connection was extraordinarily important to adoptive father Henry. Because it is obvious that his daughter Ruthie is not biologically related to him (she is half Inuit and half Jamaican, whereas Henry and his partner are Caucasian), Henry needed others to know that Ruthie was his daughter. When asked if there was something that surprised him about being a primary caregiver, Henry responded saying:

So a lot of the time when I'm with Ruthie I get a lot of strange looks. And I sometimes think the best of it and I sometimes think the worst of it. Because a lot of the time people look at me, and I assume they are looking at me because I have adopted this child and they think that's awesome. Other times the way people look at me, I get the impression that they're watching me because they think I've abducted Ruthie. That I often get, especially at the park. Not even that I've abducted Ruthie - that I'm not supposed to be around her and I've just wandered over close to this child and she has nothing to do with me. So that 
weighs on my mind a lot of the time when I'm out in public with her. So I tend to be not clingy, but I'm not hesitant to carry her or put her on my shoulders or stuff like that to sort of mark my territory to some extent; so it is very clear that Ruthie is my daughter; because I like that to be noticeable.

While successfully bonding with their child eased these men's depression (e.g., Mathieu), difficulty developing a connection with their child exacerbated it. In this regard George described being frustrated and disappointed by the lack of attachment that had developed between himself and his teenage daughter Sara. He had adopted Sara four months prior to the interview and had not yet seen any signs of her attaching to him. George found that her lack of attachment prevented him from attaching to her, and this added to his depression. However, he described a recent interaction with his daughter that left him feeling encouraged that she was beginning to form an attachment. Here, Sara was upset after George suggested that she go on a camping trip with Girl Guides this summer.

But we finally got it out [of her]. She said, "It's too far away from you." Okay - so there's the attachment. And dependency. She's becoming dependent on us, which is what we need so she can be a child; she can give up the alpha, "I've got to take care of myself." Nope, we're going to take care of you. So we're seeing - I'm seeing little signs and that is helpful.

Henry also spoke of being troubled when Ruthie did not attach to him in the first month following her adoption.

My wife got 9 months off as parental leave. So I didn't have the instant moment of feeling like a parent when we brought her into our house, because my wife was off and I was still working. But every time for the first few weeks I would come home from work and Ruthie would burst out crying. She attached to my wife very easily because she was around her all the time. But also it meant that 
when I walked in the door, the odds were increasing that my wife would go somewhere because she deserved a break at that point; so I would look after Ruthie. So Ruthie would just burst out crying the minute my wife was leaving to go somewhere. So that went on for like a month. So it prevented me from attaching to Ruthie a little bit, but not a huge amount. I mean she still would when she got really upset, she would let me cuddle her and try to soothe her a bit.

\section{Unique Features of Biological and Adoptive Fathers' Experiences}

In addition to their shared experiences, the biological and adoptive fathers each described one unique factor as important to their caregiving-related depression. For the biological fathers' this unique factor involved their Difficulty being mentally present with their children, which was described by two of the three biological fathers (Nathan and Charles, but not Mark). When asked how his depression progressed, Nathan recalled his struggle trying to stay mentally present while he was the primary caregiver to his young daughters. In this regard he said:

I remember again when my children were young and kind of climbing on me, holding my younger daughter and just feeling like in my mind I was somewhere else. I was just not present. And I think over time, I was able to be a lot more present as well with my children. Quite frankly that is something that I still work on. I come home from work at the end of the day and my mind might still be on something work-related and they want my attention. And so I have to be conscious about being present. But I would say more so back then, I was slowly able to be more present and more connected with them; rather than consciously wishing I was somewhere else or sleeping.

Charles also mentioned being unable to remain mentally engaged and merely going through the motions of everyday life. Specifically, when asked what his depression was like, Charles responded: 
Just lack of will to do things, just to - you know, doing work was hard. Experiencing joyful things was not the same. What else? You brewed a lot, you seem like you go through the motions and not much is - there's a little futility to your everyday actions kind of thing and you sort of think that way. Those were sort of the things I experienced.

For the adoptive fathers this unique factor involved their Strong need to teach their child new or fundamental skills, a factor mentioned by two of the three adoptive fathers (George and Henry but not Mathieu). For George, this need became apparent as he spoke of being extremely disappointed by the lack of respect his teenage daughter showed for him. Indeed, Sara often displayed rude behaviour like passing gas or interrupting him when he spoke. During his interview, George described an exciting instance where his daughter listened to him and retained a skill that he had taught her.

What are the signs that she's actually listening to me? She's not giving any notice that she's listening, but - one of the things I showed early on was when she said she wanted to be a chef. And she spent lots of time in the kitchen at her foster home. They told us she was very helpful in the kitchen and we saw a bit of that initially. And she was helping me chop some stuff and I showed her how a chef would hold a knife - and I'm fairly skilled at it, curling your fingers and hold the knife against your fingers, and as you're chopping down, it keeps your finger tips from getting cut [demonstrates the hand motions of chopping]. Mary, her grandmother, was visiting over Easter and her little sister Jocelyn who's two years younger. And the two of them were helping me prepare dinner. And so they had different chores, and Sara, I saw her showing Jocelyn how to cut, she said, "Now look it, I'll show you. With the big knife you hold it against your fingers and that way your fingertips don't get chopped. And you hold the knife against your fingers and move it that way ..." It's there. It's there.

When Henry was asked if he had any expectations of his relationship with his toddler, Ruthie, he explained that he expected himself to impart fundamental knowledge 
to Ruthie. Henry was visibly excited when he discussed the words he would teach her, as well as the routine he would create to effectively prepare her for school.

I was thinking this morning about - I want to teach her the word "plus." Because it's very similar to "and" of course. I want to teach her milk plus chocolate syrup is chocolate milk, so that she understands the concept of 'plus' so I can start teaching her math. Because she is picking up numbers like she is starting to count; she's up to about 5 now. And so I have expectations of myself to start doing that now. Because also, when the summer comes around I am going to be with her fulltime. She won't have her Head start program. So I need to start figuring out and structuring my day a bit with her. Even if it's just for 15 minutes we're gonna do the alphabet once a day. Otherwise I'm just going to sort of haphazardly be like, "Ok you sit there while I do the dishes and maybe we'll read a book sometime."

\section{Society's Influence on Fathers' Experiences}

These fathers also described aspects of society that added to and/or perpetuated their depression. Two themes underlay these discussions, specifically Social expectations of parents and Fathers' unmet support needs.

Social expectations of parents. All of the fathers, except Charles, described their fear of failing to meet society's expectations of new parents as contributing to their depression. In his follow-up email, adoptive father Henry described the complexities of society's expectations of new parents and how these expectations can make new parents feel like they are failing.

I find that depression can easily hit me when I don't know if I'm making a difference. Society seems to largely agree that the stay at home parent is doing something important - but not something that requires education or training; it's something important that we are supposed to naturally know how to do. When you feel for even a second that you don't know the best way to nurture a kid you 
know it's your fault. You start to think of your entire life as a failure or filled with mistakes and that everyone else is better than you are at this thing. Anyway, this isn't something that preoccupies my mind but I think men expect themselves to achieve success. But if you don't know how to measure success, what then?

Henry continued:

With regard to how and why I felt feelings of depression I would say it was the result of a feeling of futility. As I said before it's very difficult to get any sense of accomplishment [while child rearing] because you don't know when you're succeeding on a day-to-day basis. I think we all have this expectation that dayto-day you can have a task and complete it - but that's virtually impossible while dealing with a child. I don't think our culture respects long term goals as much as it thinks it does. Sorry to get political for a second but our culture and economy is based on achieving measurable goals. You can't get a loan without them. You spend thousands on school for them. A mortgage is entirely based on goals. But you can't do that with a kid and even if you set simple goals like my kid will be able to read - you often think to yourself, maybe they would have figured out how to read anyway or worse, maybe they would have learned to read better thanks to someone else.

Interestingly, Henry described his fear of failing as a father as being much stronger with his own daughter, Ruthie, than with his step-son, Lincoln. Perhaps Henry did not have the same fear with Lincoln because Lincoln's biological mother and father are more directly accountable for Lincoln's behaviour.

Um so it's more stressful with her, for sure. Not that every single time she spills her milk I'm like, “Oh my god I'm failing.” But I know the buck stops with me I guess, to some extent. However, like I said, I could tell Lincoln what to do, there's never any resistance. Because he just sort of respects me as an authority figure. And he doesn't whine the way he does with his mom and his dad. And 
also I don't have what I have with Lincoln that I do with Ruthie. With Ruthie I worry - like I think most parents do, when she does something wrong it reflects poorly on me as a parent. Lincoln I don't worry about that.

George, who before the adoption loved renovating his home and took great pride in finishing tasks, also lamented over no longer being able to measure his daily success with a concrete, visible end product.

So it's that thing that childcare doesn't have value in society. And yet you can be exhausted by it. And it's from morning 'til night that you're doing the job. So not to have value in society or great value and in my own makeup I don't value it. I don't know how to value it. I cannot give it the, well, you know, I built this closet. It has value, you can see it. People can use it. And for me that's the great pleasure; watching people use it. But childcare - when I renovated something it looks better. When I take care of this child, nothing happens. I don't see- there's no payoff ... at this point. I'm doing this other stuff that which is fascinating- to me, has no value. I'm caretaking. I'm taking care of a child. It has no value. At the end of the day I haven't done any work ... I'm exhausted, I'm tired out, I'm drained, and I haven't done work today.

Nathan, a biological father, also described his fear of failing as a parent. For Nathan, this fear was emotionally laden in that, not only did he did not want to fail as a parent, he definitely did not want to follow in the footsteps of his abusive father.

Nathan: The other thing I wonder about too is embarrassment and shame. I often think about - I felt like I was failing as well in those moments too. All of a sudden I'm a failure. And am I going to become my dad? And so what's that feeling? Is it shame? Is it embarrassment? Is it a feeling of failure? I don't know.

Interviewer: What did you think you were failing at? 
Nathan: $\quad$ At being a parent. I think I really felt like I was failing. Like why can't I get a grip on this? Why is this so overwhelming for me? I can't handle it.

Fathers' unmet support needs. All of the fathers attributed aspects of their depression to society's lack of support for fathers who are primary caregivers for their children, things that society lacks, most notably the lack of macro-level support systems and community resources, as well as the family law system's neglect of children during divorce.

Before the interview began, Nathan commented on the lack of encompassing support systems for new parents, especially for new fathers. When I asked if there was any support that he had looked for but did not find, Nathan responded:

Absolutely. More after the fact it's just made me think about the kind of preparation we need to have available for parents. I just think it's strange that you have to have a license to drive a car and for other things in life, but anybody can be a parent at any point in time. And what's really the preparation? Well there's some biological preparation; they talk about the birthing process and all that, which is really important. And what else is there so that dad's who've had traumatic pasts are prepared for the caregiver kind of role? I mean that kind of stuff I really wish I could have used more preparation in terms of self-reflection. I'm not sure I would have fully understood it before, but I think as I entered into parenting it would have given me a framework in terms of thinking about these kind of situations. And I often think so many parents are kind of floundering when they first become parents. And then you add something like depression on top of that and then where do those floundering people go? How do they understand their experiences? So I think if we did more to prepare dads and support dads - especially in the transition to becoming a dad. 
Many of the fathers wished there were more community resources available to fathers experiencing parenting-related depression. For example, George was disappointed in the lack of intimate adoption support groups available within his community. He said the only one he knew of was too large and operated like a seminar rather than an intimate place to share and discuss adoption experiences.

When asked how he coped with his feelings of depression and the other challenges he was encountering, Charles explained how working with a social worker/child psychologist helped him gain the tools he needed to effectively support his children. However, he also mentioned how expensive this private resource was, and how less costly resources are not necessarily effective.

But you know, I've got to fork that cash over every month and that's costly. And my budget is greatly reduced. That's a huge cost. So it's tough. [The social worker] will email, "there are all sorts of services and community support and _" but that's bullshit. There's nothing there, nothing pragmatic, practical and effective.

After recently going through the divorce process and gaining joint custody of his two young children, Charles was adamant about the drastic change in focus that is needed in the family law system. He was very clear that this lack of focus left him responsible for caring for his children's well-being and that this added directly to his depression. You as parents, your number one focus is - forget about the whole divorce BS - the number one focus in this process is to make sure the kids are okay; the divorce process should be secondary. The kid's welfare, never mind financial, but emotional welfare, and them having a good parental foundation and the skills and the mechanisms, and the two parents to take care of those kids so that they can survive the divorce properly so that they are not messed up when they get older; it doesn't exist. And nobody is making you aware of that. And I get 
pissed off - it verges on disgusting because I think the courts and the lawyers and even the therapists - these are the people that are harming the kids. These are the people that are harming the kids. They facilitate the destruction of the family unit. They are facilitating it. They are the accomplice in the destruction of these kids' lives. And that's the way I see it. I think it's extreme but it's the truth. You can't deny it. We should take the courts to court...

The things we have in Canada - they don't have anything in place to make the parents aware of that. To say, "This is a tough time for your kids. You need to do this." I sat in the court house for five hours going over and over, "This is how you divorce and this is the divorce process." Wonderful courthouse, lots of people, great audio visual systems, four or five different lawyers came in to describe the whole process. I knew everything about how to destroy the whole situation. But they never sit down and - they have their little slides about what's happening to the kids, that's bullshit. Complete shit. They never sit down and go, "Okay, this is impacting the kids. This is the worst thing for the kids. This is destroying their family." I've talked to many lawyers, male and female, and they say that if you're the man - they say that outright, as soon as I stepped in the lawyer's office, "If you're the man, you're going to get screwed." That's basically how it works. Which I think almost sucks because, where's the focus? Is the focus on - it doesn't have to be on the father, it doesn't have to be on the mother. It needs to be on the children.

\section{An Additional Interview}

During the interview it became clear that Derek, a 38 year-old biological father who was the primary caregiver of a young son, did not experience depression associated with having his child. Although he did not meet the participation requirements, he offered a very interesting, albeit heartbreaking, perspective on postpartum depression. Given this, his interview was transcribed and analyzed. 
Six months after giving birth to their son, Derek's partner Michelle told him that she thought she was experiencing postpartum depression. She met with her family doctor weekly, who treated the depression with medication for three months. Michelle felt much better and her doctor was considering taking her off the medication because she was doing so well. When Mason was 11 months old, Michelle accidentally locked her keys in the car with him inside. It was a very hot day and the tow truck was going to be delayed, so she called the police to break a car window. Although Mason was retrieved safely, Michelle felt like she was a terrible person and wondered who would lock their child in the vehicle. When Derek returned home from work, he found his son crying in his crib and Michelle unresponsive on their bed. Michelle had committed suicide.

Derek had some interesting remarks about his transition to fatherhood, becoming a primary caregiver, coping with his partner's suicide, the importance of social support, the double standards for single mothers and fathers, and advice for other single fathers.

While describing his transition to fatherhood, Derek explained how the caretaking responsibilities for baby Mason were balanced between himself and his partner Michelle. As a result, he was prepared for taking on the role of primary caregiver after Michelle's death.

I was a hands-on dad right away. I changed diapers, I fed him. I tried to help out as much as I could. So I already knew how to do everything. It wasn't like "Oh my god, here we go. Here's a kid, figure him out" kind of deal [after Michelle's death]. I probably changed as many diapers and fed him as many times as she had. I wanted to be the it's 50/50, if you're tired I'll take care of him, If I'm tired you'll take care of him. In my mind, it's not a just because you're the mom, it's not your responsibility to do all this. Both of us created this kid so both of us can raise him. And that's why when everything happened 
[Michelle's death], it's not like I was trying to learn a new language or something different ... It's not like it was something new to me, I just continued what I was doing.

When asked about his initial feelings about becoming the primary caregiver, Derek explained how his support system and the routine baby Mason was used to were fundamental in creating a relatively smooth transition.

No, I wasn't too worried. Like I said, I had a great support system with my parents. They raised myself and my brother. And I was 9 years older than my brother so I also got to help out with raising him so it was not like it was the first time doing it. The hardest part I thought with raising a child was the first two months. After that it's simple. It's just figuring the kid out, getting him into a routine. And getting yourself into a routine. Being able to function with minimal sleep, which I was already used to with working shift work.

During the interview, Derek frequently commented on how imperative the support he received from family and friends was. He described this support as crucial to being able to cope with Michelle's death and move forward with his life.

I didn't have any family in [City A] so I talked to my parents. And I work shift work so the only way for me to continue that was to move back [to City B] for them to help me out when I work nights and stuff they can take him. And then with sports and everything else - basically when I need someone else they are there for me. I wouldn't have been able to do it in [City A]. I wouldn't have been able to continue my line of employment. At the time it [Michelle's death] was a big shock and everything else, but I have a very close group of friends and my family and they took everything off of me. I didn't have to - they let me do my thing and they took care of everything else. It was a great support system and it is kind of what to this day has gotten me through it ... One of the cops I used to work with, his wife passed away when his kids were two years old and 
he talked to me about it. We still talk back and forth and he's remarried and moved on and whatever else. He kind of helps me through it as well.

Derek explained that keeping himself busy was, and still is, his main way of coping with Michelle's suicide.

Derek: I don't know any other way. Like if I sit down at home alone and get bored - that's one thing that I have found with coping with what I went through. If I'm bored and have time, I start to think. And that's when I think, “Okay, time to go for a run, or time to do this or that." I notice if I keep myself going, the thoughts aren't there.

Interviewer: So the distraction -

Derek: $\quad$ Yeah, it keeps me going. There are times even with long drives where I'm alone and I start thinking about this and that and whatever else. There isn't a day that goes by where I don't think about her. It's hard not to when I look at him, I just see her. When he laughs, he laughs like her. It's not something I'll ever forget.

When I asked if he perceived any differences in the community support available for single mothers and single fathers, Derek commented on the double standards he has experienced as a single father:

There's the same support, but you [fathers] have to jump through more loop holes. Like more hoops to get it. Like me taking my son across the border, prime example. I took him over, it was just after his first birthday. Went over there no problem and came back and was at the border and they asked me, "Does his mom know he is out of the country?" I said, "No." They said, "Pardon me?" I said, "She died." [The border patrol said], "Oh my god, I'm so sorry." [I said], “Ok, no problem." A couple weeks later we cross [the border] and come back again to Canada. "Does his mom know he's outside of the country?" "No" "Pardon me?" "She died" "Oh my god, I'm so sorry." Third time same thing. I 
finally said to the girl, "Listen, do me a favour and punch something into your computer that says quit asking this guy if ..."

So I work with a bunch of cops and I asked their wives, "When you take the kids across the border and you come back, do you ever get asked if their dad knows they are out of the country?" Never. Don't get me wrong, I appreciate they are doing their jobs so kids aren't getting abducted and going across [the border] when divorces happen. But I find, why ask a dad the whole time? What's the difference if they're both single parents?

I do find, like especially when [Mason] was one or two, a lot of women thought I was incompetent with a kid because I'm a male. Even at daycare they said, “Oh here, we'll do this for you." And I'm like, "Why? I can do that at home." And they're like, "Oh yeah, we forgot you can do all this stuff, it's just a lot of the other dads who pick their kids up are just taxis."

At the end of the interview, I asked Derek if there was anything he thought other single fathers might benefit from knowing. Derek once again stressed the need for a strong social support system.

Have a support system. If it's not family, they're available in the community. I've talked to people that have gone through similar situations. There are people out there that will help you. That's what you have to do. You have to find the help. Find a support system. 


\section{Discussion}

The findings of this study suggest that biological and adoptive fathers' experiences of depression in the period after having or adopting a child are more similar than they are different. Comparing these findings with those reported in the literature also suggests that these fathers' experiences of depression are not unlike those of mothers suffering from postpartum depression (PPD). For example, both the biological and adoptive fathers' characterized their depression as involving feelings of loneliness, confusion, fatigue or loss of energy, and frequent intense emotions, including feelings of helplessness, hopelessness, and being completely overwhelmed. These symptoms are entirely consistent with those observed among women with PPD (Beck, 2002; Buultjens \& Liamputtong, 2007; Leahy-Warren \& McCarthy, 2007). Also in line with the experiences of mothers with PPD, and as Foli (2010) observed in her study of the members of a support group for adoptive fathers, experiences of anger often surfaced multiple times during their narratives.

Just as strong predictors of PPD in women include a history of psychopathology, stressful life events, and low levels of social support (O'Hara \& Swain, 1996), these biological and adoptive fathers reported histories of depression, experienced significant stressful life events before the onset of their parenting-related depression, and had problems with social support related to their caregiving. Thus, as noted by Areias et al. (1996), fathers with a history of depression may well be more susceptible to the development of paternal PPD. Interestingly, in the current study a number of the fathers reported histories of childhood abuse and neglect, experiences strongly associated with depression in adulthood (Brown, Cohen, Johnson, \& Smailes, 1999), as well as other 
issues with the potential to adversely affect parenting (e.g., relational difficulties, emotional dysregulation).

The significant stressful life events that preceded these fathers' experiences of parenting-related depression were diverse and included job loss and unemployment, severe health concerns, and divorce. Added to such stressors, these fathers described the increased responsibilities and profound life changes associated with caregiving as exacerbating their experiences of depression. In this respect these fathers' experiences are, once again, entirely consistent with those of mothers suffering PPD who point to additional responsibilities such as cooking, cleaning, running errands, picking up and dropping off children, and helping with school work as contributing to their depression (e.g., Nicolson, 1998).

Although it was anticipated that these fathers would have little in the way of social support, surprisingly, all but one of the fathers in this study had high levels of perceived formal (e.g., family doctor, adoption workers, mental health workers) and/or informal sources of social support (e.g., friends, family). However, consistent with previous research on the support needs of mothers experiencing PPD (Letourneau et. al., 2007), the type of support that each father needed (e.g., help with childcare, talking with doctor about experience of depression) was specific to their own experiences of paternal or post-adoption depression and their own needs. For example, Charles, a single father of two, preferred receiving instrumental support in the form of childcare from his friends and family, however, the same type of support was not needed to the same degree by fathers living with supportive partners who provided instrumental support more regularly. 
Although these fathers also described their social support as helping their transition to fatherhood and reducing their feelings of depression, finding also noted by other researchers (Bielawksa-Barorowicz \& Kossakowska-Petrycka, 2006; DeaterDeckard, Pickering, Dunn, \& Golding, 1998; Durkin, Morse, \& Buist, 2001). For example, in one of the few studies of fathers' experiences of paternal postpartum depression (PPPD), Gao, Chan, and Mao (2009) found that fathers with more social support reported slightly lower levels of stress and were moderately less depressed (as measured using the Edinburgh Postnatal Depression Scale). In view of this, it is important to remember that "human beings [i.e., both mothers and fathers] need space, time, and support to adapt ... change [associated with becoming parents]. They need help when faced with added burdens, responsibility and social isolation" (Nicolson, 1998, p. 109).

Analyses also suggested that all six of these fathers described the importance of developing and maintaining a connection with their children. Although this aspect of fathers' experiences has not been reported in earlier research, it is unsurprising, particularly for adoptive fathers (e.g., Foli, 2010; Johnson \& Fein, 1991). When a parent's attachment to an adoptive child, or an adoptive child's attachment to a parent, does not develop as quickly as anticipated, a parent may be vulnerable to depression. For example, while interviewing parents experiencing post-adoption depression, Foli (2010) listened to a mother describe her frustration about her daughter not immediately attaching to her, and how she eventually came to the realize that this occurred because her daughter did not trust her yet. This type of struggle and subsequent realizations were common among the adoptive fathers in the current study. 
Perhaps the most salient similarity between these fathers' experiences and those of mothers' suffering PPD is the contribution of the asymmetry between their expectations and the reality of their caregiving experiences to depression. BerggrenClive (1998) found that biological mothers suffering postpartum depression had a host of unmet expectations, including issues related to labour and delivery, the support they received from family members and friends, their relationships with significant others, and the physical changes in their bodies after pregnancy and giving birth. Similarly, Foli's (2010) interviews with 21 adoptive or kinship parents (only one of whom was male) revealed that these parents had unfulfilled or unrealistic expectations of themselves as parents, the child, friends and family, and society. Surprisingly, this finding has not yet been reported in studies of fathers' experiences of parenting-related depression. In the current study, however, the gap between fathers' expectations and the reality of their experiences surfaced on many occasions and in regard to many aspects of these fathers' experiences, including their child's behaviour, the time and energy involved in caregiving, and the nature of their attachment with their child.

In addition to the shared aspect of fathers' and mothers' experiences of parentingrelated depression, the biological and adoptive fathers in the current study each described a factor uniquely related to their experiences, both of which have not been discussed in previous research. Specifically, biological fathers described having difficulty being mentally present with their children. This finding may stem from the fact that the diminished ability to think or concentrate is one of the diagnostic criteria for a major depressive episode in the DSM-IV-TR (American Psychiatric Association, 2000). Adoptive fathers, on the other hand, expressed a strong need to teach their child 
fundamental and new skills. Why these adoptive fathers had this need and its relation to these fathers' experiences of depression are unclear. One might speculate that this need to impart knowledge to their children stems from these fathers' inability to influence their children's genetic makeup. Similarly, one might speculate that their fear of failing to teach their children is what contributes to their depression.

These fathers also described two societal factors as contributing to their depression. The first involved the contribution of society's unreasonable expectations of new parents to these fathers' fear that they were failing as a parents. According to the fathers in this study, these social expectations include the notion that good parenting is something that comes "naturally." As a result, when these fathers had difficulty naturally knowing how to be good parents, they attributed their shortcomings to themselves. Added to this, these fathers noted how the lack of any overt signs or measures of successful parenting made it difficult for them to know if they were being successful as parents, which also contributed to their depression. Similar findings have been observed among women with PPD. Nicolson (1998), for example, commented on how society assumes that women know how to care for and raise their children simply because women have the ability to become pregnant and give birth.

The second social factor contributing to these fathers' experiences of parentingrelated depression involved these fathers' unmet support needs. For example, some fathers attributed aspects of their depression to the limited community support available to fathers experiencing depression. In addition, one father attributed his depression to 
the family law system's neglect of children and fathers' rights during divorce proceedings.

Finally, unlike previous research with fathers and mothers suffering parentingrelated depression, the fathers in the current study did not describe the loss of identity as contributing to their depression. Nicolson (1998) reported that some of the women with PPD whom she interviewed experienced a loss of autonomous identity and occupational identity. According to Nicolson, "this loss was a loss of how they had experienced their lives before the baby, as successful and independent" (p. 93). Similarly, based on a meta-synthesis Beck (2002) reported that sense of pervasive loss was one of the major themes underlying women's experiences of PPD, including the loss of autonomy and identity identified by Nicolson (1999) and a loss of control (Beck, 1993). In the current study only one father, George, spoke of losing his identity. George said that "being shaped as a dad meant losing who [he] was," because parenting his adoptive daughter “takes away my craft. I'm not doing what I do," referring to his occupational identity as a designer and construction worker.

Like all research, the current study has both strengths and weaknesses. Among the strengths are the efforts I made to enhance the credibility (e.g., using indepth interviews, an iterative design, and member checks), dependability (maintaining a methods journal and memoing during the analyses), confirmability (maintaining a personal reflexive journal, providing informative quotes), and transferability (providing sufficient information about the participants and the research context) of the study and its findings. Additional confidence in the validity of these findings comes from their consistency with the findings of earlier research. 
Although the small sample size may be regarded as a limitation, theoretical sufficiency (Dey, 1999) was not far from being achieved in that by the sixth interview I was simply fleshing out the nature of some of the already established themes. No doubt the variability in these fathers' demographic characteristics and life circumstances went some way to ensuring that a range of perspectives and experiences were represented in the data. Nevertheless, gathering more data would be worthwhile, especially regarding the themes that were unique to biological and adoptive fathers.

To the extent that the findings of this research are valid, they have a number of implications for both practices and research with fathers experiencing parenting-related depression. The applied implications include issues related to social support. Although these fathers reported having adequate levels of formal and informal support, they nevertheless pointed to the need for more community support programs for new fathers, especially for those experiencing depression. Given this, the implementation of accessible community programs staffed by competent professionals should be a priority of mental health and child service agencies. However, this in itself may be insufficient because, regardless of age, nationality, ethnicity and social background, men are less likely than women to seek professional help for physical and mental health problems (Husaini et al., 1994; D’Arcy \& Schmitz, 1979; Neighbors \& Howard, 1987), including both formal (e.g., therapy) and informal help (e.g., from friends) for depression (Padesky \& Hammen, 1981; Weissman \& Klerman, 1977).

To account for gender differences in help seeking, and in line with the accounts of the fathers in this study, Addis and Mahalik (2003) point to the inconsistency between help seeking and social expectations regarding 
masculinity, which include the notion that men are self-reliant, tough, and in control of their emotions, among other things. According to Addis and Mahalik (2003, pp. 11):

A man is least likely to seek help for problems that he sees as unusual, especially when he also perceives them as central to his identity. He is also unlikely to seek help if groups of men who are important to him endorse norms of selfreliance or other norms that suggest his problem is non-normative. Finally, help seeking is less likely to the degree that a man calculates that rejection from an important social group, as well as his view of himself as deviant, are costs too great to risk in relation to the help he might receive. This is especially true if he feels he will sacrifice his autonomy by seeking help.

Consistent with Addis and Mahalik's (2003) observations, in experimental research help seeking was more likely when participants were led to believe that their failure at a task was normative (i.e., that many people failed the task) rather than non-normative (i.e., that few people failed the task) (Tessler \& Schwartz, 1972). Given this, efforts to increase new fathers' help seeking might include making fathers aware of the normativeness of paternal postpartum depression, including the fact that parental depression is almost as common among new fathers (10\%; Paulson \& Bazemore, 2010) as it is among new mothers (13\%; O’Hara \& Swain, 1996). Indeed, if more fathers regarded PPPD as normative, the rate of PPPD may be found to be much higher.

A second practical issue concerns the language used to describe the depression experienced by new parents. Since the genesis of this research project, the majority of those I have discussed the study with are extremely surprised by the topic. I have been questioned by many men and women with worried eyes and raised brows, "Are you sure fathers can experience postpartum depression?" Not long after writing up the results of 
this study an older father said, "You're going to have to say a lot to convince me that men experience postpartum depression. It is only a women's thing." Interestingly, people were much more likely to see the merit of this research when I described it as a study of "depression associated with having or adopting a child" as compared to a study of "fathers experiencing paternal postpartum depression." Because the expression "postpartum depression" implies that such depression is caused by the hormonal fluctuations associated with giving birth, there is a clear need for researchers and professionals to problematize the label "paternal postpartum depression." In addition, because the results of this study and others (e.g., Nicholson, 1998) support a psychosocial account of parenting-related depression, it may be more accurate to use a phrase such as "depression associated with having or adopting a child" or "parenting-related depression."

The findings of this study also suggest a number of areas for future research. As mentioned earlier, conducting more interviews with fathers experiencing parentingrelated depression would be worthwhile, especially regarding the themes that were unique to biological and adoptive fathers. In this regard it would be useful to learn why biological, but not adoptive, fathers reported difficulty being mentally present with their children. Similarly, it would be useful to learn why adoptive, but not biological, fathers expressed a strong need to teach their child fundamental and new skills and why these adoptive fathers had this need and its relation to their experiences of depression. Although only one father commented on the loss of his occupational identity and its contribution to his feelings of depression, because the loss of identity has been identified as a major component of mothers' experiences of PPD (Nicolson, 1998) it would also be 
worthwhile for researchers to explicitly pursue the potential contribution of the loss of identity to fathers' experiences of depression. Other avenues for future research include studies designed to examine the contribution of gender roles to fathers' willingness to seek social support for caregiving and assistance for any depression they may experience, as well as the contribution of experiences of child abuse and neglect to both fathers' and mothers' parenting-related depression.

Finally, previous research shows that prevalence rates for paternal postpartum depression are dynamic depending on the elapsed time postpartum. According to Paulson and Bazemore's (2010) meta-analysis, the highest rate of paternal depression occurred between 3 and 6 months postpartum (26\%) and the lowest rate of paternal depression was observed in the first 3 months postpartum (8\%). Although the authors did not provide an explanation for this shift in prevalence rates across time, they suggest that depression may be the result of fathers being depleted by the day-to-day tasks of caring and adjusting to the life changes associated parenting. This explanation, however, cannot explain why the rate of paternal depression decreased to $9 \%$ at 6 to 12 months postpartum (Paulson \& Bazemore, 2010). In view of this, longitudinal research, with multiple interviews throughout the first two or three years of parenthood, might usefully explore fathers' transitions and depression through different phases.

Given the time required to recruit participants for this type of research, researchers might consider eliminating the requirement that participants be the primary caregiver to their child. This criterion was included in the current study in order to parallel the circumstances of mothers experiencing postpartum depression who, traditionally, have been primary caregivers diagnosed with PPD within 12 months of 
giving birth. Dropping this requirement may not only make it easier to recruit participants, it may also avoid the complexities associated with the expression "primary caregiver." In her research exploring fathering, care, and domestic responsibility, Doucet identified a great deal of diversity in the meaning of the term "primary caregiver." For example, a father may call himself a primary caregiver because he is "responsible for the primary care of his children for significant periods of time" (Doucet, 2006, p. 76). Another father who does not carry out any domestic responsibilities may call himself a primary caregiver because he looks after his children, and another father may describe himself as a primary caregiver when in reality he is engaged in some form of shared parenting (e.g., a single father may employ a nanny to cook, clean, and care for the child while he is at work).

\section{Personal Endnote}

While reflecting on this research process, I am reminded of the great journey it was both academically and personally. This study was the most onerous project that I have taken on academically, and by far the one I am most passionate about. Passion for the topic and an earnest desire to represent these fathers' experiences fueled me to see the project through to completion; though the process was emotionally trying. Throughout this research process, I found myself desperately wanting to lessen these fathers' experiences of depression and to take away the painful experiences that no one should ever have to go through in life. No matter the time of day, I could not get these fathers' narratives out of my mind; I could not simply tuck these research related thoughts away until they were needed. Although many people have told me that my sensitivity is a flaw, I firmly believe that being a sensitive person made me a better researcher. I was emotionally invested in this project, and turning off my empathy and sensitivity was not 
an option. I had a beautiful moment of clarity after an interview with a father who had a heartbreaking past: it was not my job to save them from their pain, it was my job to sensitively represent them in this academic document. This research has affected me in ways I did not anticipate; it has enlightened me greatly, it has challenged me daily, and changed me forever. 


\section{References}

Addis, M. E., \& Mahalik, J. R. (2003). Men, masculinity, and the contexts of help seeking. American Psychologist, 58, 5-14. doi:10.1037/0003-066X.58.1.5

Affonso, D., De, A., Horowitz, J., \& Mayberry, L. (2000). An international study exploring levels of postpartum depressive symptomatology. Journal of Psychosomatic Research, 49, 207- 216. doi:10.1016/S0022-3999(00)00176-8

American Psychiatric Association. (2000). Diagnostic and statistical manual of mental disorders (4th ed., rev.). Washington, DC: American Psychiatric Association.

Appleby, L., Warner, R., Whitton, A., \& Faragher, B. (1997). A controlled study of fluoxetine and cognitive-behavioural counselling in the treatment of postnatal depression. British Medical Journal, 314, 932-936.

doi: http://dx.doi.org/10.1136/bmj.314.7085.932

Areias, M., Kumar, R., Barros, H., \& Figueiredo, E. (1996). Correlates of postnatal depression in mothers and fathers. British Journal of Psychiatry, 169, 36-41. doi: 10.1192/bjp.169.1.36

Ballard, C., \& Davis, R. (1996). Postnatal depression in fathers. International Review of Psychiatry, 8, 65-71.

Ballard, C., Davis, R., Cullen, P., Mohan, R., \& Dean, C. (1994). Prevalence of postnatal psychiatric morbidity in mothers and fathers. British Journal of Psychiatry, 164, $782-788$.

Banister, E. M. (1999). Evolving reflexivity: Negotiating meaning of women's midlife experience. Qualitative Inquiry, 5(1), 3-23. doi:10.1177/107780049900500101 
Beck, C. (2002). Postpartum depression: A metasynthesis. Qualitative Health Research, 12, 453- 472. doi: 10.1177/104973202129120016

Beck, C. T. (1993). Teetering on the edge: A substantive theory of postpartum depression. Nursing Research, 42, 42-48. doi: 10.1097/00006199-19930100000008

Beck, C. T. (1996). Postpartum depressed mothers' experience interacting with their children. Nursing Research, 45, 98-104.

Beck, C., \& Gable, R. (2001). Further validation of the Postpartum Depression Screening Scale. Nursing Research, 50(3), 155-164.

Beck, A.T., Ward, C.H., Mendelson, M., Mock, J., \& Erbaugh, J. (1961). An inventory for measuring depression. Archives of general psychiatry, 4, 561-571.

Berggren-Clive, K. (1998). Out of the darkness and into the light: Women's experiences with depression of childbirth. Canadian Journal of Community Mental Health, 17, 103-120.

Bielawksa-Barorowicz, E., \& Kossakowska-Petrycka, K. (2006). Depressive mood in men after the birth of their offspring in relation to a partner's depression, social support, fathers' personality and prenatal expectations. Journal of Reproductive and Infant Psychology, 24(1), 21-29. doi:10.1080/02646830500475179

Birks, M., Chapman, Y., \& Francis, K. (2008). Memoing in qualitative research: Probing data and processes. Journal of Research in Nursing, 13(1), 68-75.

Bloch, M., Schmidt, P., Danaceau, M., Murphy, J., Nieman, L., \& Rubinow, D. (2000). Effects of gonadal steroids in women with a history of postpartum depression. American Journal of Psychiatry, 157, 924-930. doi: 10.1176/appi.ajp.157.6.924 
Braun, V., \& Clarke, V. (2008). Thematic analysis in psychology. Qualitative Research in Psychology, 3(2), 77-101.

Brown, J., Cohen, P., Johnson, J., \& Smailes, E. (1999). Childhood abuse and neglect: Specificity of effects on adolescent and young adult depression and suicidality. Journal of the American Academy of Child \& Adolescent Psychiatry, 38(12), 1490-1496.

Buultjens, M., \& Liamputtong, P. (2007). When giving life starts to take the life out of you: Women's experiences of depression after childbirth. Midwifery, 23(1), 77-91. doi: 10.1016/j.midw.2006.04.002

Campbell, S., \& Cohn, J. (1991). Prevalence and correlates of postpartum depression in first-time mothers. Journal of Abnormal Psychology, 100(4), 594-599. doi: 10.1037/0021-843X.100.4.594

Chabrol, H., Teissedre, F., Saint-Jean, M., Teisseyre, N., Roge, B., \& Mullet, E. (2002). Prevention and treatment of post-partum depression: a controlled randomized study on women at risk. Psychological Medicine, 32, 1039-1047. doi:

Chalmers, B., \& Chalmers, B. (1985). Post-Partum Depression: A revised perspective. Journal of Psychosomatic Obstetrics and Gynaecology, 5, 93-105.

Charmaz, K. (2006). Constructing grounded theory. London: Sage.

Cialdini, R. B., \& Trost, M. R. (1999). Social influence: Social norms, conformity, and compliance. In D. Gilbert, S. Fiske, \& G. Lindzy (Eds.), The handbook of social psychology (Vol. 2, pp. 151-192). Boston: McGraw-Hill. 
Cochran, S. V., \& Rabinowitz, F. E. (2000). Men and depression: Clinical and empirical perspectives. Practical resources for the mental health professional. San Diego, CA: Academic Press.

Cohen, S., Kamarck, T., \& Mermelstein, R. (1983). A global measure of perceived stress. Journal of Health and Social Behavior, 24(4), 385-396.

Cox, J., Holden, J., \& Sagovsky, R. (1987). Detection of postnatal depression. Development of the 10-item Edinburgh Postnatal Depression Scale. British Journal of Psychiatry, 150, 782-786. doi:10.1192/bjp.150.6.782

Davey, S. J., Dziurawiec, S., \& O’Brien-Malone, A. (2006). Men’s voices: Postnatal depression from the perspective of male partners. Qualitative Health Research, 16(2), 206-220.

D’Arcy, C. D., \& Schmitz, J. A. (1979). Sex differences in the utilization of health services for psychiatric problems in Saskatchewan. American Journal of Psychology, 24, 19-27.

Deater-Deckard, K., Pickering, K., Dunn, J.F., \& Golding, J. (1998). Family structure and depressive symptoms in men preceding and following the birth of a child. The Avon longitudinal study of pregnancy and childhood study team. American Journal of Psychiatry, 155(6), 818-823.

Dennis, C., Janssen, P., \& Singer, J. (2004). Identifying women at-risk for postpartum depression in the immediate postpartum period. Acta Psychiatrica Scandinavica, 110(5), 338-346.

Doucet, A. (2006). Do men mother? Fatherhood, care, and domestic responsibility. Toronto: University of Toronto Press. 
Durkin, S., Morse, C., \& Buist, A. (2001). The factor structure of prenatal psychological and psychosocial functioning in first-time expectant parents. Journal of Reproductive and Infant Psychology, 19, 121-134. doi:10.1080/02646830123982

Edmondson, O. J., Psychogiou, L., Vlachos, H., Netsi, E., \& Ramchandani, P. G. (2010). Depression in fathers in the postnatal period: Assessment of the Edinburgh Postnatal Depression Scale as a screening measure. Journal of Affective disorders, 125(1-3), 365 .

Edhborg, M. (2008). Comparisons of different instruments to measure blues and to predict depressive symptoms 2 months postpartum: A study of new mothers and fathers. Scandinavian Journal of Caring Sciences, 22(2), 186-195. doi: 10.1111/j.1471-6712.2007.00512.x

Ellingson, L. L. (1998). “Then you know how I feel”: Empathy, identification, and reflexivity in fieldwork. Qualitative Inquiry, 4(4), 492-514.

Finlay, L. (2002). Negotiating the swamp: The opportunity and challenge of reflexivity in research practice. Qualitative Research, 2(2), 209-230.

Foli, K. (2010). Depression in adoptive parents: A model of understanding through Grounded Theory. Western Journal of Nursing Research, 32(3) 379-400. doi: $10.1177 / 0193945909351299$

Gair, S. (1999). Distress and depression in new motherhood: Research with adoptive mothers highlights important contributing factors. Child and Family Social Work, 4(1), 55-66. doi: 10.1046/j.1365-2206.1999.00098.x 
Goodman, J. (2008). Influences of maternal postpartum depression on fathers and on father-infant interaction. Infant Mental Health Journal, 29(6), 624-643. doi: 10.1002/imhj.20199

Green, S., \& McCabe, R. (2012, June). Assessment and treatment of perinatal anxiety workshop. Annual Convention of the Canadian Psychological Association, Halifax, Nova Scotia, Canada.

Handford, P. (1985). Postpartum depression: What is it, what helps? The Canadian Nurse, 81(1), 30-33.

Harris, B. (1989). The use of rating scales to identify post-natal depression. British journal of psychiatry, 154, 813-817.

Harris, B. (1996). Hormonal aspects of postnatal depression. International Review of Psychiatry, 8(1), 27-36.

Hurst, S. A. (1999). Legacy of betrayal : A grounded theory of becoming demoralized from the perspective of women who have been depressed. Canadian Psychology, 40(2), 179-191. doi: 10.1037/h0086835

Husaini, B. A., Moore, S. T., \& Cain, V. A. (1994). Psychiatric symptoms and helpseeing behavior among the elderly: An analysis of racial and gender differences. Journal of Gerontological Social Work, 21, 177-193.

Johnson, D., \& Fein, E. (1991). The concept of attachment: Applications to adoption. Children and Youth Services Review, 13, 397-412.

Kendler, K. S., Neale, M. C., Kessler, R. C., Heath, A. C., \& Eaves, L. J. (1992). A population-based twin study of major depression in women: The impact of varying definitions of illness. Archives of General Psychiatry, 49(4), 257. 
Kessler, R. C., Brown, R. L., \& Boman, C. L. (1981). Sex differences in psychiatric helpseeking: Evidence from four large-scale surveys. Journal of Health and Social Behavior, 22, 49-64.

Kvale, S. (1996). Interviews: An introduction to qualitative research interviewing. Thousand Oaks, CA: Sage.

Leahy-Warren, P., \& McCarthy, G. (2007). Postnatal depression: Prevalence, mothers' perspectives, and treatments. Archives of Psychiatric Nursing, 21(2), 91-100.

Letourneau, N., Duffett-Leger, L., Stewart, M., Hegadoren, K., Dennis, C-L., Rinaldi, C., \& Stoppard, J. (2007). Canadian mothers' perceived support needs during postpartum depression. Journal of Obstetric, Gynecologic, \& Neonatal Nursing, 36(5), 441-449. doi: 10.1111/j.1552-6909.2007.00174.x

Leung, S., Arthur, D., \& Martinson, I. (2005). Stress in women with postpartum depression: A phenomenological study. Journal of Advanced Nursing, 51(4), 353360.

Lusskin, S., \& Misri, S. (2011a). Postpartum blues and depression. UpToDate database. Literature review current through 2012, January. Retrieved 2012, March from Grand River Hospital, Waterloo, Ontario.

Lusskin, S., \& Misri, S. (2011b). Postpartum psychosis: Epidemiology, clinical manifestations, and assessment. UpToDate database. Literature review current through 2012, January. Retrieved 2012, March from Grand River Hospital, Waterloo, Ontario.

Lusskin, S., Pundiak, T., \& Habib, S. (2007). Perinatal depression: Hiding in plain sight. Canadian Journal of Psychiatry, 52(8), 479-488. 
Matthey, S., Barnett, B., Kavanagh, D., \& Howie, P. (2001). Validation of the Edinburgh Postnatal Depression Scale for men, and comparison of item endorsement with their partners. Journal of Affective Disorders, 64, 175-184.

Matthey, S., Barnett, B., Ungerer , J., \& Waters, B. (2000). Paternal and maternal depressed mood during the transition to parenthood. Journal of Affective Disorders, 60, 75-85. doi: 10.1016/S0165-0327(99)00159-7

Mauthner, N. (1995). Postnatal depression: The significance of social contacts between mothers. Women's Studies International Forum, 18, 311-323. doi: 10.1016/0277$5395(95) 80075-Z$

Mauthner, N. (1998). It's a woman's cry for help: A relational perspective on postnatal depression. Feminism \& Psychology, 8, 325-355. doi: 10.1177/0959353598083006

McCoy, S., Beal, J., \& Watson, G. (2003). Endocrine factors and postpartum depression: A selected review. The Journal of Reproductive Medicine, 48(6), 402-408.

McKay, K., Ross, L., \& Goldberg, A. (2010). Adaptation to parenthood during the postadoption period: A review of the literature. Adoption Quarterly,13(2), 125-144.

Meighan, M., Davis, M., Thomas, S., \& Droppelman, P. (1999). Living with postpartum depression: The father's experience. American Journal of Maternity and Child Nursing, 24, 202-208.

Meissner, W. (2006). Psychoanalysis and the mind-body relation: Psychosomatic perspectives. Bulletin of the Menninger Clinic, 70(4), 295-315. doi: http://dx.doi.org/10.1521/bumc.2006.70.4.295

Miller, L. (2002). Postpartum depression. Journal of the American Medical Association, 287(6), 762-765. 
Morrow, S. L. (2005). Quality and trustworthiness in qualitative research in counseling psychology. Journal of Counseling Psychology, 52(2), 250-260. doi:10.1037/00220167.52 .2 .250

Morse, J.M. (1991). Strategies for sampling. In J.M. Morse (Ed.), Qualitative nursing research: A contemporary dialogue (Rev. ed., pp. 106-118). Thousand Oaks, CA: Sage.

Neighbors, H. W., \& Howard, C. S. (1987). Sex differences in professional help seeking among adult Black Americans. American Journal of Community Psychology, 15, 403-417.

Nicolson, P. (1998). Post-natal depression: Psychology, science and the transition to motherhood. New York, NY: Routledge.

Nicolson, P. (1999). Loss, happiness and postpartum depression: The ultimate paradox. Canadian Psychology, 40, 162-178. doi:10.1037/h0086834

O’Hara, M., Schlechte, J., Lewis, D., \& Wright, E. (1991). Prospective study of postpartum blues: Biologic and psychosocial factors. Archives of General Psychiatry, 48, 801-806.

O’Hara, M., \& Swain, A. (1996). Rates and risks of postpartum depression: A metaanalysis. International Review of Psychiatry, 8(1), 37-54. doi: $10.3109 / 09540269609037816$

Padesky, C. A., \& Hammen, C. L. (1981). Sex differences in depressive symptom expression and help-seeking among college students. Sex Roles, 7, 309-320. 
Paulson, J., \& Bazemore, S. (2010). Prenatal and postpartum depression in fathers and its association with maternal depression: A meta-analysis. Journal of the American Medical Association, 303(19), 1961-1969. doi:10.1001/jama.2010.605

Payne, J., Fields, E., Meuchel, J., Jaffe, C., \& Jha, M. (2010). Post adoption depression. Archives of Women's Mental Health, 13(2), 147-151. doi: 10.1007/s00737-009$0137-7$

Ponterotto, J. G. (2005). Qualitative research in counseling psychology: A primer on research paradigms and philosophy of science. Journal of Counseling Psychology, 52(2), 126-136.

Radloff, L.S. (1977). The CES-D Scale: A self-report depression scale for research in the general population. Applied Psychological Measurement, 1, 385-401.

Ramchandani, P., O’Connor, T., Heron, J., Murray, L., \& Evans, J. (2008). Depression in men in the postnatal period and later child psychopathology: A population cohort study. Journal of the American Academy of Child \& Adolescent Psychiatry, 47(4), 390-398. doi: 10.1097/CHI.0b013e31816429c2

Rubin, H.J., \& Rubin, I.S. (1995). Qualitative interviewing: The art of hearing data. Thousand Oaks, CA: Sage.

Sandelowski, M., Docherty, S., \& Emden, C. (1997). Qualitative meta-synthesis: Issues and techniques. Research in Nursing \& Health, 20, 365-371. doi: 10.1002/(SICI)1098-240X(199708)20:4<365::AID-NUR9>3.0.CO;2-E

Schumacher, M., Zubaran, C., \& White, G. (2008). Bringing birth-related paternal depression to the fore. Women and Birth: Journal of the Australian College of Midwives, 21(2), 65-70. doi: 10.1016/j.wombi.2008.03.008 
Schwandt, T. A. (1997). Qualitative inquiry: A dictionary of terms (pp. 135-136).

Thousand Oaks, CA: Sage.

Senecky, Y., Agassi, H., Inbar, D., Horesh, N., Diamond, G., Bergman, Y., et al. (2009).

Post-adoption depression among adoptive mothers. Journal of Affective Disorders, 115, 62-68. doi: 10.1016/j.jad.2008.09.002

Spinelli, M. (2003). Infantcide: Psychosocial and legal perspectives on mothers who kill. Washington (DC): American Psychiatric Publishing, Inc.

Steiner, M., Dunn, E., \& Born, L. (2003). Hormones and mood: From menarche to menopause and beyond. Journal of Affective Disorders, 74, 67-83.

Steiner, M., \& Steiner M. (1990). Postpartum psychiatric disorders. Canadian Journal of Psychiatry, 35(1), 89-95.

Stuart, S. (2012). Interpersonal psychotherapy for postpartum depression. Clinical Psychology and Psychotherapy, 19, 134-140. doi: 10.1002/cpp.1778

Tessler, R. C., \& Schwartz, S. H. (1972). Help seeking, self-esteem, and achievement motivation: An attributional analysis. Journal of Personality and Social Psychology, 21, 318-326.

Treloar, S., Martin, N., Bucholz, P., Madden, P., \& Heath, A. (1999). Genetic influences on post-natal depressive symptoms: Findings from an Australian twin sample. Psychological Medicine, 29(3), 645-654.

Viguera, A., Cohen, L., Baldessarini, R., \& Nonacs, R. (2002). Managing bipolar disorder during pregnancy: Weighing the risks and benefits. Canadian Journal of Psychiatry, 47, 426-436. 
Weaver, J., \& Ussher, J. (1997). How motherhood changes life - A discourse analytic study with mothers of young children. Journal of Reproductive and Infant Psychology, 15, 51-68.

Weissman, M. M., \& Klerman, G. L. (1977). Sex differences and the epidemiology of depression. Archives of General Psychiatry, 34, 98-111.

Wilson, L., Reid, A., Midmer, D., Biringer, A., Carroll, J, \& Stewart, D. (1996). Antenatal psychosocial risk factors associated with adverse postpartum family outcomes. Canadian Medical Association Journal, 154(6), 785-799.

Wisner, K. L., Parry, B. L., \& Piontek, C. M. (2002). Postpartum depression. New England Journal of Medicine, 347(3), 194-199.

Xiao, S.Y., \& Yang, D.S. (1987). The effect of social support on physical and psychological health. Journal of Chinese Psychiatry, 1, 184-187.

Yonkers, K., Wisner, K., Stewart, D., Oberlander, T., Dell, D., Stotland, N., Ramin, S., Chaudron, L., \& Lockwood, C. (2009). The management of depression during pregnancy: A report from the American Psychiatric Association and the American College of Obstetricians and Gynecologists. General Hospital Psychiatry, 31, 403413. 


\section{Appendix A: Research Materials}

\section{Permission to Leave/Post Sheets Describing Study}

Carleton

Canada's Capital University

Hello,

My name is Lilly Pease and I am a graduate student in the Psychology Department at Carleton University. For my MA thesis research, I am studying primary caregiving fathers' experiences of depression after having or adopting a child.

For this research, I am having conversations with such fathers to explore their experiences of transitioning to fatherhood, decisions to become a primary caregiver, their expectations regarding this transition, experiences of depression, and how they coped with this. After this discussion, participants will be asked to complete the Edinburgh Postnatal Depression Scale (Cox, Holden, \& Sagovsky, 1987), which is a five minute self-report measure designed to screen for depression. This research will take place at a private location on the Carleton University campus, or a mutually agreed upon place for both participant and researcher. All who participate will be compensated with twenty dollars.

In order to obtain participants, I am distributing a one page sheet with a brief description of my study and my contact information. I would be grateful if you would help me with my research by giving me permission to post and/or leave copies of this information sheet on your premises.

This study has been reviewed and approved by the Carleton University Research Ethics Committee for Psychological Research and assigned \# 13-063. To satisfy the requirement of this committee, I need your signature to indicate that you have given me permission to leave and/or post the sheet describing my study on your premises.

If you have any questions I can be reached at Lilly_Pease@carleton.ca or (613) 520-2600 ext. 2679. My faculty advisor is Dr. Connie M. Kristiansen, who can be reached at Connie_Kristiansen@carleton.ca or (613) 520-2600 ext. 2674.

Thank you for your consideration.

Sincerely,

Lilly Pease, MA Candidate 


\section{Permission to Leave/Post Sheet Describing Study}

Having been informed of the nature of the study regarding fathers' experiences of depression after having or adopting a child, I grant Lilly Pease from the Department of Psychology at Carleton University to leave notices calling for fathers to take part in her research.

Location:

Print name here:

Position:

Signature: Date: 
Carleton

U N IVERS ITY

Canada's Capital University

\section{Recruitment Poster}

This study has been approved by the Carleton

University Ethics Committee for Psychological Research and assigned \# 13-063.

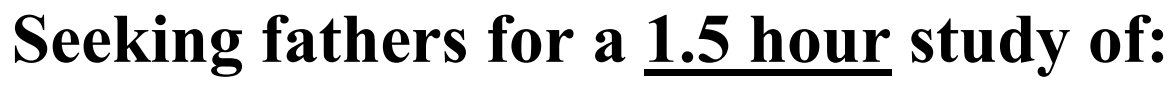

\section{Fathers' experiences of depression after having or adopting a child}

\section{All participants will be compensated $\$ \mathbf{2 0 . 0 0}$}

- Are you a father?

- Are you the primary caregiver?

- Have you experienced depression within 12 months of having or adopting a child?

If so and you want to learn more, contact:

Lilly_Pease@carleton.ca

(613) 520-2600 ext. 2679 


\section{Email Script}

Hello

My name is Lilly Pease and I am a graduate student in the Psychology Department at Carleton University. For my MA thesis research, I am studying primary caregiving fathers' experiences of depression after having or adopting a child.

For this research, I am having conversations with biological and adoptive fathers to explore their experiences of transitioning to fatherhood, decisions to become a primary caregiver, experiences of depression, and coping with this depression. After this discussion, these men will be asked to complete the Edinburgh Postnatal Depression Scale (Cox, Holden, \& Sagovsky, 1987) which is a five minute self-report measure designed to screen for postpartum depression. This research will take place at a private location on the Carleton University campus, or a mutually agreed upon location for both participant and researcher. All who participate will be compensated with twenty dollars.

In order to obtain participants, I am emailing to ask you to pass along the details of my study to anyone interested in participating. I am recruiting biological or adoptive fathers who are primary caregivers, and have experienced depression within 12 months of having or adopting their child. Please feel free to pass along the attached document to those interested in participating.

If you have any questions I can be reached at Lilly_Pease@carleton.ca or (613) 520-2600 ext. 2679. My faculty advisor is Dr. Connie M. Kristiansen, who can be reached at Connie_Kristiansen@carleton.ca or (613) 520-2600 ext. 2674.

Sincerely,

Lilly Pease

MA Candidate

This study has been reviewed and approved by the Carleton University Research Ethics Committee for Psychological Research and assigned \# 13-063. 


\section{Email Attachment}

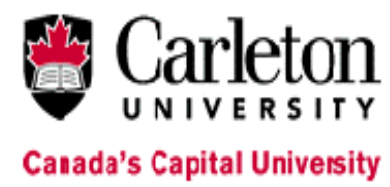

\section{Seeking participants for a 1.5 hour interview study of:}

\section{Fathers' experiences of depression after having or adopting a child}

- Are you a father?

- Do you self-identify as a primary caregiver?

- Have you experienced depression within 12 months of having or adopting a child?

If so and you want to learn more, please contact:

Lilly_Pease@carleton.ca

or (613) 520-2600 ext. 2679

All participants will be compensated $\mathbf{\$ 2 0 . 0 0}$

This study has been reviewed and approved by the Carleton University Research Ethics Committee for Psychological Research and assigned \# 13-063 
This study has been reviewed and approved by the Carleton University Research Ethics Committee for Psychological Research and assigned \# 13-063.

\section{Informed Consent:}

\section{Fathers' Experiences of Depression after Having or Adopting a Child}

Investigators: Lilly Pease, MA Candidate, Psychology Dept., Carleton University Connie Kristiansen, PhD, Faculty Advisor, Psychology Dept., Carleton University

The purpose of this consent form is to ensure that you understand the purpose of this study and the nature of your involvement. This consent form must provide you with sufficient information so as to allow you to determine whether you wish to participate. Please ask the researcher if you_have any questions or are in need of clarification.

This study is being conducted by Lilly Pease as part of the requirements for the MA degree in Psychology under the supervision of Dr. Connie Kristiansen, both of whom are at the Department of Psychology at Carleton University in Ottawa. The purpose of this study is to gain insight into biological and adoptive fathers' experiences of depression after having or adopting a child. In this study you will be asked to take part in a one and a half hour conversation exploring your experience of depression after having or adopting a child.

The conversations, which will be held at a private and mutually agreed upon location (e.g., Carleton University campus), will focus on the experience of transitioning to fatherhood, decisions to become a primary caregiver, expectations regarding this transition, your experience of depression, and how you coped with this. After this discussion, you will be asked to complete the Edinburgh Postnatal Depression Scale (Cox, Holden, \& Sagovsky, 1987), which is a five minute self-report measure of depression, and questions about your background (e.g., education, employment). In return for your time and effort, you will be given $\$ 20$.

Due to the sensitive nature of this topic, this study may be upsetting for some people. It is therefore important that you understand that your participation in this study is entirely voluntary. You are welcome to skip questions and may stop participating at any time, for any reason, without explanation and without any effect on your 
compensation. You should also know that at the end of this study you will be provided with information regarding resources that you may contact in the event that you are distressed as a result of your participation.

You should also know that everything you say will be kept entirely confidential and all information that you provide will be used for research purposes only. In order to preserve your anonymity, a pseudonym will be used in any report of the results. In addition, the audio recording of the conversation will be destroyed upon completion of the study (anticipated to be December, 2013) and any information that could identify you will be removed from the typed transcript and all other research materials (e.g., questionnaires). This consent form, which will be stored under lock and key separately from your interview transcript and all other research materials, will be shredded one year after your participation in this study.

Should you require any further information regarding the study, please do not hesitate to contact Lilly Pease (MA candidate) at Lilly_Pease@carleton.ca or (613) 5202600 x 2679, or Dr. Connie Kristiansen (faculty advisor) at Connie_Kristiansen@carleton.ca or (613) 520-2600 ext. 2674. If you have any ethical concerns regarding the study, please contact Dr. Avi Parush (Chair, Carleton University Research Ethics Committee for Psychological Research) at Avi_Parush@carleton.ca or (613) 520-2600 ext. 6026. If you have any questions or comments about any other aspect of the study, you are welcome to contact Dr. Anne Bowker (Chair, Department of Psychology, Carleton University) at (613) 520-2600 ext. 8218.

Consent: My signature below indicates that I have read and fully understood the above statement and freely consent to participate in this study.

Participant's Name

Witness' Name
Participant's Signature

Witness' Signature
Date

Date 


\section{Consent to Audio Record:}

I hereby consent to the audio recording of this conversation. I understand that it is being recorded for accuracy purposes only and that the recording will be destroyed upon completion of this study.

\begin{tabular}{l}
\hline Participant's Name \\
\hline
\end{tabular}

Witness' Name

\begin{tabular}{ccc}
\hline Participant's Signature & & Date \\
\hline Witness' Signature & & Date
\end{tabular}

\section{Consent for Follow-Up Contact}

I hereby grant the researcher permission to contact me to give me the opportunity to add or delete comments from my interview, clarify aspects of my account, or to provide feedback about the results of the study if needed.

Participant's Name

Participant's Signature

Date

Contact Information : 


\section{Interview Guide for Biological Fathers}

\section{Go through Consent}

\section{Warming Up}

- What made you decide to participate in this study?

\section{Transition to Becoming a Primary Caregiver}

Can you tell me about how you came to be a primary caregiver? (e.g., did you make the decision yourself or was it a collaborative decision? Did you make the decision willingly or did you feel pressured into it?)

- What were your initial feelings about becoming a primary caregiver? (Confident? Ambivalent?)

- What did other people think about it? (e.g., at work, friends, relatives)

\section{Expectations}

Did you have any expectations, hopes or fears, about becoming a primary caregiver?

Were any of your actual experiences in line with these expectations? (which ones, how so, examples)

Did any of your experiences turn out to be different from what you expected? (which ones, in what ways, examples)

- How did you deal with these unmet expectations?

\section{Experience of Depression}

Can you tell me about when you started feeling depressed?

- What was going on in your life then?

What was the depression like? What did you feel like? What were you thinking? Did it affect your behaviour? Your relationships with others?

Were there any things that made your depression worse? Any situations that were overwhelming? 
Were there any things that made you feel better? Any situations, things or people that made it better?

How did the depression progress over time?

\section{Coping}

How did you cope with your feelings? (e.g., do distracting things, talk with anyone?)

Did you tell anyone how you were feeling? Who? Why them? Why not others?

Did you ever ask anyone for help?

- If yes: Who? Why them? Did they help? How so? Ask anyone else? Why not ask others?

- If not: Why not? What stopped you?

Did/does anyone give you any kind of support? (Family? Friends? Community? Professionals?) What kind of support? What did they do? Was it helpful?

Were there any things that you felt you needed but didn't get?

\section{Toning Down}

Is there anything else you think I should know about your experiences that I haven't asked about? Anything else you want to share with me?

People sometimes talk about clouds having a silver lining - about how good things can sometimes result from the most difficult of experiences. Was there any silver lining to your experience of depression or the difficulties you had parenting in the year after your child came? Did anything good come of these challenging experiences?

Was there something that surprised you in a positive way about being a primary caregiver?

What are you looking forward to experiencing with your child(ren)?

\section{Debriefing}




\section{Interview Guide for Adoptive Fathers}

\section{Go through Consent}

\section{Warming Up}

- What made you decide to participate in this study?

\section{Transition to Fatherhood and Becoming a Primary Caregiver}

$>$ I would like to know more about your transition into becoming a father

How did your decision to adopt a child come about? (e.g., Did you make the decision yourself or was it a collaborative decision? Did you make the decision willingly or did you feel pressured into it?)

- What were your initial feelings about becoming a primary caregiver? (Confident? Ambivalent?)

- What did other people think about it? (e.g., at work, friends, relatives)

\section{Expectations}

Did you have any expectations, hopes or fears, about becoming a primary caregiver?

Were any of your actual experiences in line with these expectations? (which ones, how so, examples)

Did any of your experiences turn out to be different from what you expected? (which ones, in what ways, examples)

- How did you deal with these unmet expectations?

\section{Experience of Depression}

Can you tell me about when you started feeling depressed?

- What was going on in your life then?

What was the depression like? What did you feel like? What were you thinking? Did it affect your behaviour? Your relationships with others?

Were there any things that made your depression worse? Any situations that were overwhelming? 
Were there any things that made you feel better? Any situations, things or people that made it better?

How did the depression progress over time?

\section{Coping}

How did you cope with your feelings? (e.g., do distracting things, talk with anyone?)

Did you tell anyone how you were feeling? Who? Why them? Why not others?

Did you ever ask anyone for help?

- If yes: Who? Why them? Did they help? How so? Ask anyone else? Why not ask others?

- If not: Why not? What stopped you?

Did/does anyone give you any kind of support? (Family? Friends? Community? Professionals?) What kind of support? What did they do? Was it helpful?

Were there any things that you felt you needed but didn't get?

\section{Toning Down}

Is there anything else you think I should know about your experiences that I haven't asked about? Anything else you want to share with me?

People sometimes talk about clouds having a silver lining - about how good things can sometimes result from the most difficult of experiences. Was there any silver lining to your experience of depression or the difficulties you had parenting in the year after your child came? Did anything good come of these challenging experiences?

Was there something that surprised you in a positive way about being a primary caregiver?

What are you looking forward to experiencing with your child(ren)?

\section{Debriefing}




\section{Background Questions}

The following questions ask about your background. I am asking for this information so I can describe the general backgrounds of the people who took part in this study, information that will be included when reporting the results of the study.

- Your age: years

- Number of children:

- Childrens' age(s):

- $\quad$ Age of child(ren) when adopted (if applicable):

- Your ethnicity:

- Your marital or relational status:

- Your highest level of education:

- Your occupation (if applicable)

- Your partner's highest level of education (if applicable):

- Your partner's occupation (if applicable):

- Have you ever been formally diagnosed as having depression? (e.g., by a psychologist, physician): $\quad$ YES NO

- Have you had any other experiences of depression prior to the one associated with having or adopting your child?

YES (circle one): Once Twice Several times

NO 


\section{Paternal Feelings of Depression Associated with Having or Adopting a Child}

The following questions ask about the feelings you had during the time you were depressed after having or adopting a child. Please select the answer that comes closest to how you felt at that time.

Here is an example, already completed.

I felt happy:

○ Yes, all the time

- Yes, most of the time

○ No, not very often

- No, not at all

This would mean: "I felt happy most of the time" after having/adopting my child.

\section{After having/adopting my child:}

1. I was able to laugh and see the funny side of things

- As much as I always could

Not quite so much now

○ Definitely not so much now

○ Not at all

2. I looked forward with enjoyment to things

○ As much as I ever did

○ Somewhat less than I used to

○ Definitely less than I used to

○ Hardly at all

3. I blamed myself unnecessarily when things go/went wrong

○ Yes, most of the time

- Yes, some of the time

- Not very often

- No, never 
4. I was anxious or worried for no good reason

○ No, not at all

○ Hardly ever

○ Yes, sometimes

○ Yes, very often

5. I felt scared or panicky for no reason

○ Yes, quite a lot

○ Yes, sometimes

○ No, not much

○ No, not at all

6. I felt overwhelmed

- Yes, most of the time I haven't been able to cope at all

- Yes, sometimes I haven't been coping as well as usual

○ No, most of the time I have coped quite well

○ No, I have been coping as well as ever

7. I was so unhappy that I had difficulty sleeping

○ Yes, most of the time

○ Yes, sometimes

○ Not very often

○ No, not at all

8. I felt sad or miserable

○ Yes, most of the time

○ Yes, quite often

- Not very often

○ No, not at all 
9. I was so unhappy, that I cried

- Yes, most of the time

- Yes, quite often

○ Only occasionally

○ No, never

10. The thought of harming myself occurred to me

- Yes, quite often

- Sometimes

○ Hardly ever

○ Never 
This study has been reviewed and approved by the Carleton University Research Ethics Committee for Psychological Research and assigned \# 13-063.

\section{Debriefing: Fathers' Experiences of Depression after Having or Adopting a Child}

The purpose of this study is to gain insight into how biological and adoptive fathers experience depression in the period of time after having or adopting their child. Although previous research has established that as many as $10 \%$ of fathers experience paternal depression, to date this research has failed to shed light on the breadth and depth of these men's lived experiences. Therefore, the present study is designed to account for this gap in knowledge and gain further insight into how biological and adoptive fathers experience depression after having or adopting a child in their own terms and in greater detail. It is my hope that focusing on primary care-giving biological and adoptive fathers' experiences of depression may provide information on these men's needs and how best to meet these needs.

If you would like more information about this area of research, you can consult the following journal articles (available at most university libraries):

Ballard, C., Davis, R., Cullen, P., Mohan, R., \& Dean, C. (1994). Prevalence of postnatal psychiatric morbidity in mothers and fathers. British Journal of Psychiatry, 164, $782-788$

Ballard, C., \& Davis, R. (1996). Postnatal depression in fathers. International Review of Psychiatry, 8, 65-71.

Foli, K. (2010). Depression in adoptive parents: A model of understanding through Grounded Theory. Western Journal of Nursing Research, 32(3), 379-400.

For more information about this study, please feel welcome to contact Lilly Pease (MA candidate) at Lilly_Pease@carleton.ca or (613) 520-2600 x 2679 or Dr. Connie Kristiansen (faculty advisor) at Connie_Kristiansen@carleton.ca or (613) 520-2600 ext. 2674. If you have any ethical concerns regarding the study, please contact Dr. Avi Parush (Chair, Carleton University Research Ethics Committee for Psychological Research) at Avi_Parush@carleton.ca or (613) 520-2600 ext. 6026. If you have any questions or comments about any other aspect of the study, you are welcome to contact 
Dr. Anne Bowker (Chair, Department of Psychology, Carleton University) at (613) 5202600 ext. 8218.

Finally, some people may feel some discomfort or distress after talking about the experiences of depression they had after having or adopting a child. If you would like discuss any distress or discomfort that may have resulted from participating in this study, you may wish to contact the Ottawa \& Region Distress Centre at 613-238-3311 (Website: www.dcottawa.on.ca) or the Ottawa Mental Health Crisis Line at 613-722-6914 (24-hour toll-free line: 1-866-996-0991; Website: http://www.crisisline.ca).

Thank you very much for your participation in this study.

Sincerely,

Lilly Pease (MA candidate) 


\section{Post Interview Comment Sheet Completed by Researcher}

$\underline{\text { First Impressions }}$

$\underline{\text { Mood / Tone of the Interview }}$

$\underline{\text { Reactions of Participant to Interview (I's Questions \& Pp's Responses) }}$

My Reactions to Participant Responses (Internal / External)

Strengths of the Interview

Weaknesses of the Interview

$\underline{\text { Additional Comments }}$ 